\title{
Estimating value-added returns to workforce training programs with causal machine learning
}

Mintaka Angell, Samantha Gold, Justine S. Hastings, Mark Howison, Scott Jensen, Daniel Molitor, Amelia Roberts

RESEARCH IMPROVING PEOPLE'S LIVES, PROVIDENCE, RI, USA

Contact: connect@ripl.org

The mismatch between the skills that employers seek and the skills that workers possess will increase substantially as demand for technically skilled workers accelerates. Skill mismatches disproportionately affect low-income workers and those within industries where relative demand growth for technical skills is strongest. As a result, much emphasis is placed on reskilling workers to ease transitions into new careers. However, utilization of training programs may be sub-optimal if workers are uncertain about the returns to their investment in training. While the U.S. spends billions of dollars annually on reskilling programs and unemployment insurance, there are few measures of program effectiveness that workers or government can use to guide training investment and ensure valuable reskilling outcomes. We demonstrate a causal machine learning method for estimating the value-added returns to training programs in Rhode Island, where enrollment increases future quarterly earnings by $\$ 605$ on average, ranging from $-\$ 1,570$ to $\$ 3,470$ for individual programs. In a nationwide survey $(N=2,014)$, workers prefer information on the value-added returns to earnings following training enrollment, establishing the importance of our estimates for guiding training decisions. For every $10 \%$ increase in expected earnings, workers are $17.4 \%$ more likely to express interest in training. State and local governments can provide this preferred information on value-added returns using our method and existing administrative data.

CCS CONCEPTS $•$ Applied computing $\rightarrow$ Computers in other domains $\rightarrow$ Computing in government $\bullet$ Information systems $\rightarrow$ Information systems applications $\rightarrow$ Decision support systems Human-centered computing $\rightarrow$ Interaction design $\rightarrow$ Empirical studies in interaction design

Additional Keywords and Phrases: Skills gap, reskilling, administrative data, return on investment, outcomes-based financing, Pay for Success, Workforce Investment Act, Wagner-Peyser Act, Unemployment Insurance 


\section{INTRODUCTION}

The U.S. spends billions of dollars annually on reskilling programs, unemployment insurance (UI), and reemployment services [1]. Federal and state governments offer employment services and labor training programs to support reskilling for displaced workers and workers in declining industries. Programs are run by contractors, private for-profit, and notfor-profit firms. These programs impact a large population of Americans at vulnerable points in their lives and careers. In Program Year 2019, there were 4.7 million participants in federally-funded programs under the Workforce Innovation and Opportunity Act and Wagner-Peyser Act [2].

The need for training that enables workers to keep up with an ever-evolving demand for workplace skills is only likely to increase. Forecasts project an imminent global skilled labor shortage [3], in which tens of millions of U.S. workers may be displaced and in need of reskilling for the future of work in the coming decades [4]. Changes in technology and the mismatch between in-demand skills and the skills that workers currently possess have exacerbated inequalities in the labor market [5]-[8].

A recent policy position in the U.S. is that workforce training programs are essential to bridging the growing gap between workers' skills and employers' needs but are hindered by a significant information gap on program effectiveness [9]-[11]. This lack of information on the value of training programs may discourage workers from enrolling due to risk aversion. There are sparse data and few measures of program success for guiding training investment decisions, monitoring training effectiveness, or ensuring that training delivers valuable skills and improved employment outcomes for enrollees. To solve this problem, these policy recommendations call for the use of "return on investment" (ROI) measures to communicate the value of training. However, because of the sparseness of available ROI information, it is currently unknown how potential training enrollees would respond to this information.

Government administrative data might supply information about which programs are most effective, including ROI. Labor training data (data collected on federal and state reemployment and training programs), wage roll data (employment data collected for payroll tax and unemployment insurance purposes), and unemployment insurance (UI) records are housed in state labor departments. Their format is often standardized across states as UI and training programs have federal reporting requirements, promising the potential of a scalable path to creating needed performance metrics such as ROI.

In this paper, we investigate two research questions related to the policy need for improving the delivery of workforce training programs:

1. Is it possible to estimate the value-added returns for individual training programs using existing government administrative data?

2. If ROI information could be provided, would workers be more likely to use ROI to choose among available training programs, compared to existing information such as program cost, duration, and location?

To answer the first question, we demonstrate an approach to estimating the value-added returns to enrollment in training programs by combining comprehensive administrative data with causal machine learning methods, which we apply to state-funded labor training programs in Rhode Island under the Real Jobs Rhode Island program. For the second, we measure the demand for information on ROI among prospective training enrollees in a nationwide survey $(N=2,014)$. Overall, we find that it is possible to estimate value-added returns from existing administrative data and that workers prefer this information over other criteria, such as program cost, duration, or location. Our approach is readily scalable to other state and local governments and applies to a broad range of training and reskilling programs, certification programs, and traditional degree-based education programs. 


\section{RELATED WORK}

Several studies of returns to worker training funded under the Workforce Investment Act (WIA) have been conducted with administrative data, including four that are reviewed and compared in detail by Barnow and Smith [13] and two more recent studies [14]-[15]. In all six cases, the administrative data available do not include wage records for all workers, but only for WIA participants or other subsets of the working population, such as UI claimants. In contrast, our data contain wage records for all workers in the State of Rhode Island. Additionally, prior work has focused on heterogenous treatment effects for enrollee characteristics like age and sex but not at the individual program level. We apply recent advances in causal machine learning methods to estimate program-level effects.

Studies of other re-employment services have shown mixed results. For example, studies of mandated participation in re-employment services under the Reemployment Services and Eligibility Assessment program (and its predecessors) have found mixed results on earnings, employment outcomes, and UI duration [16]-[22]. In contrast, earlier experimental studies of the National Supported Work Demonstration showed that intensive job training had large positive benefits for women on social assistance [23]-[25]. However, in all cases, these studies are retrospective and isolated. They cannot, for example, be used to help displaced workers seeking training today decide which program to enroll in. They also do not provide a market mechanism to correctly incentivize training providers to innovate and improve.

For our second research question, we are not aware of any prior study of workers' preferences when selecting among available training programs. Career portals that provide information on training programs limit it to program description, cost, and duration, with no measures of effectiveness towards gainful employment to help individuals and policymakers understand the benefits versus the costs of investing in each program. One concern with that approach is that displaying cost with no measure of effectiveness could lead to cost inflation if workers use cost as a signal of effectiveness because no other reliable effectiveness measure is available [12].

\section{METHODS AND DATA}

\subsection{Estimating value-added returns}

Value-added measures of workforce training programs are often unavailable to workers. To help fill this void, we applied methods from causal machine learning to estimate value-added to wages from workforce training programs implemented in Rhode Island. We used administrative records from the Rhode Island Department of Labor and Training (RIDLT) to measure labor training program enrollment, participant demographics, and labor and earnings outcomes.

We focused on training programs offered through the Real Jobs Rhode Island (Real Jobs RI) program [26]-[27], launched by RIDLT in 2016. Real Jobs RI is a workforce and economic development program designed to invest in talent development through education and skills training initiatives. It establishes partnerships led by industry stakeholders who design workforce solutions for key sectors in Rhode Island. Activities consist of education and training for individuals seeking employment in-demand careers and upskilling currently employed workers to advance their careers and remain competitive in their industry. Partnerships are evaluated based on the number of participants who enroll in their training activities, the number of participants who successfully complete the activities, the number of participants who become employed, and the number of participants who receive a wage increase or promotion. Each Real Jobs RI partnership can manage and implement more than one training program. In our analysis, we estimated differential effectiveness at both the partnership and program level. 
Our identification strategy was to compare those who enrolled in Real Jobs RI to similar individuals from the wage roll records who did not participate in training. We considered the period from 2016 (when Real Jobs RI began) through 2018, allowing us to evaluate a full year of post-training wage outcomes before the start of the COVID-19 pandemic.

To construct the analysis panel, we assembled all observations of individuals in the RIDLT administrative wage roll records between 2016 Q1 and 2018 Q4. For each wage observation at the individual, year-quarter level, we created the following lagged variables across the four prior quarters: (a) total quarterly wages (summed across all employers), (b) the first four digits of the highest-paying employer's North American Industry Classification (NAICS) code, (c) the employer registration number (ERN) for the highest-paying employer; and (d) an indicator for filing an unemployment insurance (UI) claim in that quarter. We also included time fixed effects for the year-quarter.

If an individual was unemployed during a given quarter (or otherwise did not show up in the Rhode Island wage rolls, for example if they were employed in another state), we encoded NAICS and ERN as missing and wages as zero. To account for individuals who may have been employed in another state, we filtered out individuals with no wage records in either the prior or subsequent four quarters. If an employer had fewer than 20 employees observed during the period, we replaced their ERN with a censored category. To account for occasional data entry issues in the wage rolls that led to erroneously high wages, as well as for true wage outliers, we top-coded wages at the 99.5th percentile.

We joined these wage-derived variables at the individual/quarter level to the enrollment table from Real Jobs RI to create treatment indicators for enrollment in each partnership/program, as well as an overall treatment indicator for enrollment in any partnership/program. We measured post-training wage outcomes as the average quarterly wages across the four quarters following the enrollment quarter. The final analysis panel contained 4,405 treated individuals and a randomly down-sampled set of 20,000 control individuals.

We used two methods from causal inference to estimate the impact of Real Jobs RI partnerships/programs on wage outcomes. First, we used a matching estimator where individuals enrolling in training programs are "matched" to those not enrolling in training programs using baseline characteristics that are strong predictors of post-training earnings. These matched individuals serve as a control group whose earnings approximate what earnings likely would have been for the treated individuals had they not enrolled. In a matching estimator, the researcher chooses the variables to match on and the required tightness of the match. This approach is intuitive for a general audience to understand, and it is well documented and utilized in the causal identification literature [28].

Matching estimators require significant researcher input to select controls and matching bandwidths. Recent advances in causal algorithms use machine learning to select controls automatically and optimally from a wide set of possible control functions. This increases flexibility and sustainability, allowing for repeated applications of the machine learning algorithm to automatically and optimally adapt the selected controls and functional form to account for changes in market conditions over time and across states. As a result, causal machine learning methods may be more scalable and robust for government to implement in the long run.

We used a recently developed method, Double/Debiased Machine Learning (DML), from the causal machine learning literature [29]. This method is useful in a context where many factors may explain training participation and future wages. Machine learning algorithms can detect complex patterns in data that help control omitted variable bias in a high-dimensional data setting. Moreover, DML enables a structured approach to estimating heterogeneous treatment effects in this setting [30]. We used a linear regression with a ridge (L2) penalty in the second stage of DML to estimate the heterogeneous impacts of individual Real Jobs RI partnerships/programs. A ridge penalty elegantly handles small cell sizes within the algorithm, shrinking the estimates for partnerships/programs in proportion to the signal to noise ratio. The ridge penalty function is equivalent to performing Bayesian shrinkage with a normal prior in value-added 
models, as is traditionally applied in the education literature (see, for example, [31]-[34]). Thus, the DML algorithm is an effective way to estimate value-added while also accounting for potential noise in estimates from small programs.

For the first stage of DML, we estimated two distinct predictive models. For the first model, we used the Random Forest algorithm to classify a binary variable, $d_{i q}$, indicating if an individual $i$ was enrolled in any Real Jobs RI partnership/program in quarter $q$. We refer to this model as the propensity model and use the following specification:

$$
d_{i q}=\beta_{0}+f\left(W_{i q}, N_{i q}, E_{i q}, U_{i q}, M_{i q}, Q_{i q}\right)+\epsilon_{i q}
$$

where $W_{i q}$ refers to lagged wages at the individual-quarter level. We include industry (NAICS) fixed effects, $N_{i q}$, and employer fixed effects, $E_{i q}$, for the lagged quarters. $U_{i q}$ is an indicator of whether an individual filed an unemployment claim in a given quarter. $M_{i q}$ indicates whether an individual is missing wage data in a given quarter. $Q_{i q}$ are yearquarter fixed effects. The function $f(\cdot)$ estimated by the Random Forest algorithm allows for flexible and non-linear interactions between all variables included in the model.

For the second of our first stage models, we use Random Forest to predict future wages, $y_{i q}$. We refer to this model as the outcome model and use the following specification:

$$
y_{i q}=\beta_{0}+g\left(W_{i q}, N_{i q}, E_{i q}, U_{i q}, M_{i q}, Q_{i q}\right)+\mu_{i q}
$$

with the same covariates as in the propensity model. As in the propensity model, our outcome model's functional form $g(\cdot)$ allows for flexible and non-linear interactions between all variables included in the model.

To estimate the overall average treatment effect on the treated (ATT), we performed an ordinary-least squares regression with the following specification:

$$
\mu_{i q}=\beta_{0}+\beta_{1} \epsilon_{i q}
$$

where $\mu_{i q}$ and $\epsilon_{i q}$ are the residuals from the first stage models described above. This allows us to obtain $\beta_{1}$, the coefficient of interest, as well as its corresponding standard error.

One of the principal advantages of the DML framework is its flexibility, particularly in its ability to estimate heterogeneity of treatment effects within specified groups. The two primary dimensions we want to estimate heterogeneity of treatment impact within are training programs and training partnerships. To estimate the treatment effect within each individual training program or partnership, we estimate the following specification with a regularized ridge regression:

$$
\mu_{i q}=\beta_{0}+\beta_{1} \epsilon_{i q}+\sum_{j} \beta_{2, j}\left(\epsilon_{i q} * T_{j}\right)
$$

where $\mu_{i q}$ and $\epsilon_{i q}$ are the residuals from the first stage models described above, and $T_{j}$ are indicators for each Real Jobs RI partnership/program. This allows us to obtain $\beta_{2, j}$, the coefficients of interest for heterogenous treatment effects of each partnership/program. This regularized regression approach accounts for uncertainty in the regression parameters and dampens them to account for the sample size and noise within partnerships/programs.

\subsection{Survey and choice-based conjoint design}

We designed a nationwide survey and choice-based conjoint design to measure demand for information about workforce training programs. We contracted with Dynata Inc. to recruit and field this online survey to 2,014 individuals between March 12 and April 17, 2020. Survey respondents were selected to represent the U.S. population of workers 18 years or 
older who are currently unemployed or employed but have filed for UI benefits at least once in the past three years and whose annual household income is less than $\$ 75,000$ per year.

The survey consisted of two main sections. First, we collected information about respondent demographics, labor market participation, and experience with workforce training programs. Second, the survey asked individuals questions about workforce participation. We collected information about current employment status, their current field of occupation, their knowledge about and perception of training and reskilling programs, what they would hope to gain from reskilling, and what types of information they would hope to see about reskilling programs to "feel confident (they) will be able to choose the program that is best for (them)."

Second, we conducted a choice-based conjoint design experiment to estimate demand for workforce training. Conjoint analysis is widely used in market research to measure potential demand for consumer response to new products or product features. Commercial applications of conjoint analysis inform major product and marketing decisions [35][36]. To assess how consumers value product features, such as characteristics of a labor training program, a participant is shown several different product profiles with differing and overlapping bundles of features and an associated price and asked to choose which product, if any, they would select. The responses are then analyzed using standard demand estimation techniques to understand which product features consumers value most when deciding which option (if any) to choose.

We used the conjoint design to study how important different types of information were to individuals when choosing to enroll in a training program. Respondents were shown three hypothetical training programs at a time. We randomly varied the training program features shown and the values those features took on to estimate demand for training programs as a function of what features are displayed. We tested six models of displaying information about the training program. These models are shown in Table 1 and Column 7 shows the range of values from which information content was drawn. Appendix Figures 1-4 show the distribution of values used in the conjoint models for program cost, duration, travel time, and estimated post-training earnings. Appendix Table 1 shows summary statistics for the contents of each information feature in each of the six conjoint models.

Table 1: Conjoint Design Models

\begin{tabular}{|l|c|c|c|c|c|c|l|}
\hline & $(1)$ & $(2)$ & $(3)$ & $(4)$ & $(5)$ & $(6)$ & \multicolumn{1}{|c|}{$(7)$} \\
\hline Information feature & Model 1 & Model 2 & Model 3 & Model 4 & Model 5 & Model 6 & Possible Values \\
\hline Cost & Yes & Yes & Yes & Yes & Yes & Yes & $\$ 0-\$ 20,000$ \\
\hline Duration & Yes & Yes & Yes & Yes & Yes & Yes & $2-12$ weeks \\
\hline Travel Time & Yes & Yes & Yes & Yes & Yes & Yes & $10-60$ minutes \\
\hline Completion Rate & No & Yes & Yes & No & No & No & $25-95 \%$ \\
\hline $\begin{array}{l}\text { Typical Earnings of past } \\
\text { enrollees, after training }\end{array}$ & No & No & Yes & Yes & No & Yes & $\begin{array}{l}95-130 \% \text { of pre- } \\
\text { training earnings }\end{array}$ \\
\hline $\begin{array}{l}\text { Typical Earnings of past } \\
\text { enrollees had they not enrolled }\end{array}$ & No & No & No & Yes & No & No & $\begin{array}{l}95-130 \% \text { of pre- } \\
\text { training earnings }\end{array}$ \\
\hline $\begin{array}{l}\text { Percentage increase in earnings } \\
\text { for past enrollees }\end{array}$ & No & No & No & No & Yes & No & $5-30 \%$ \\
\hline $\begin{array}{l}\text { Unemployment rate for past } \\
\text { enrollees }\end{array}$ & No & No & No & No & No & Yes & $0-25 \%$ \\
\hline
\end{tabular}




\subsection{Availability}

Source code for all analyses is available from GitHub at https://github.com/ripl-org/roi-training-programs. Survey data can be requested from the survey implementor, Dynata Inc. De-identified administrative records are available through a data use agreement with the Rhode Island Department of Labor and Training.

\section{RESULTS}

\subsection{Matching estimates of value-added}

Figure 1 plots mean quarterly earnings for individuals enrolled in each of the five largest Real Jobs RI training programs. To find a comparable group of workers that did not enroll in Real Jobs RI, we estimated a predictive model using the Least Absolute Shrinkage and Selection Operator (LASSO) machine learning algorithm with five-fold cross-validation to search for the strongest predictors of earnings over a large set of demographic and prior employment features. We found that past wages-specifically, wages from the preceding four quarters-were consistently the most important predictors of future wages. Therefore, we matched enrollees in reskilling programs to those who did not enroll in reskilling programs on wages in each of the four quarters prior to enrollment (within a bandwidth of $\$ 500$ ), first four digits of NAICS code, and unemployment status. We found at least one match for $91 \%$ of Real Jobs RI participants.

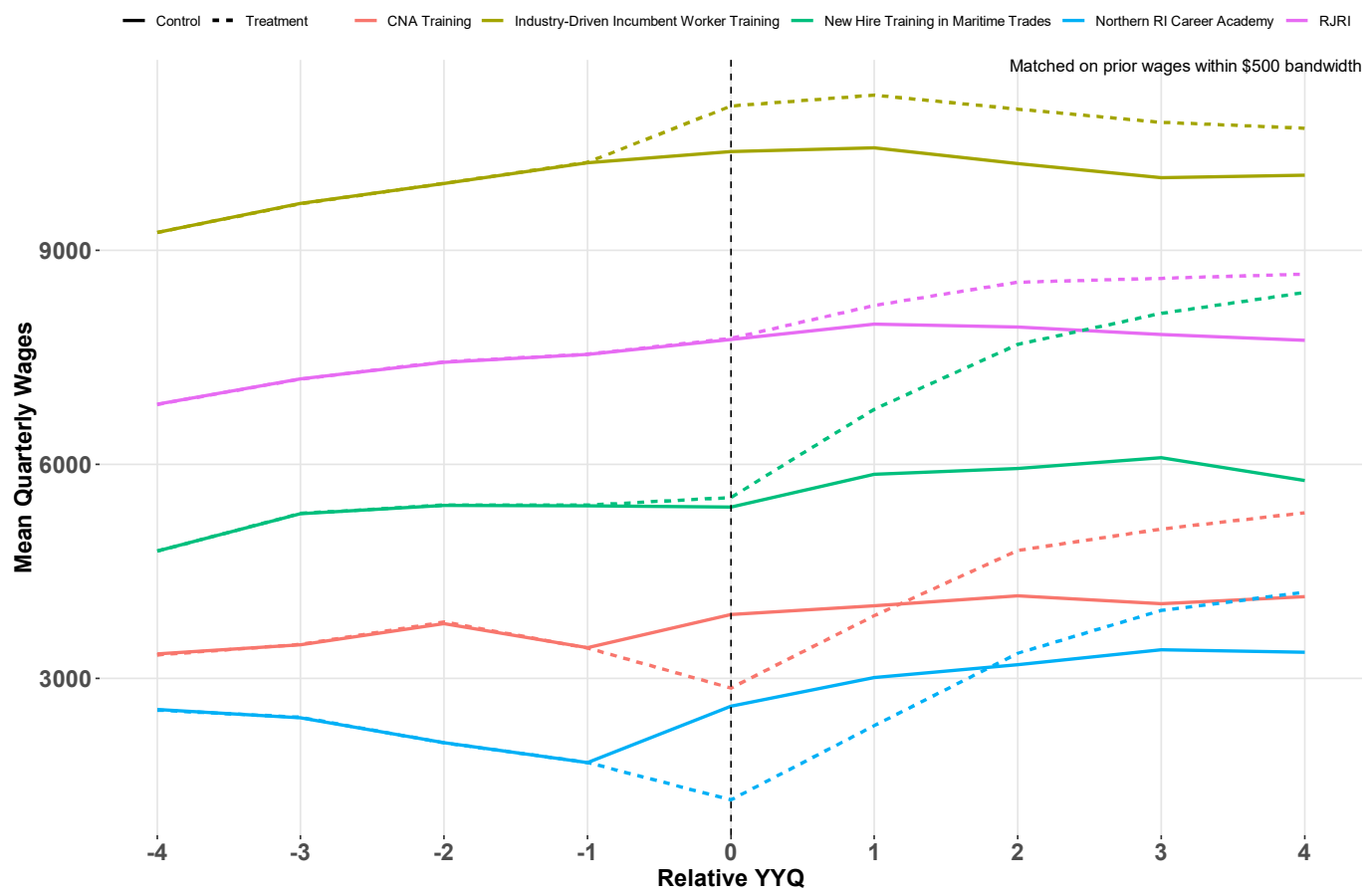

Figure 1: Matching approach to estimating the effect of Real Jobs RI training programs. Dashed lines show average quarterly wages for Real Jobs RI training participants for five select programs. Solid lines show the equivalent quarterly wage trends for a matched sample of Rhode Island workers. 
(A) Programs

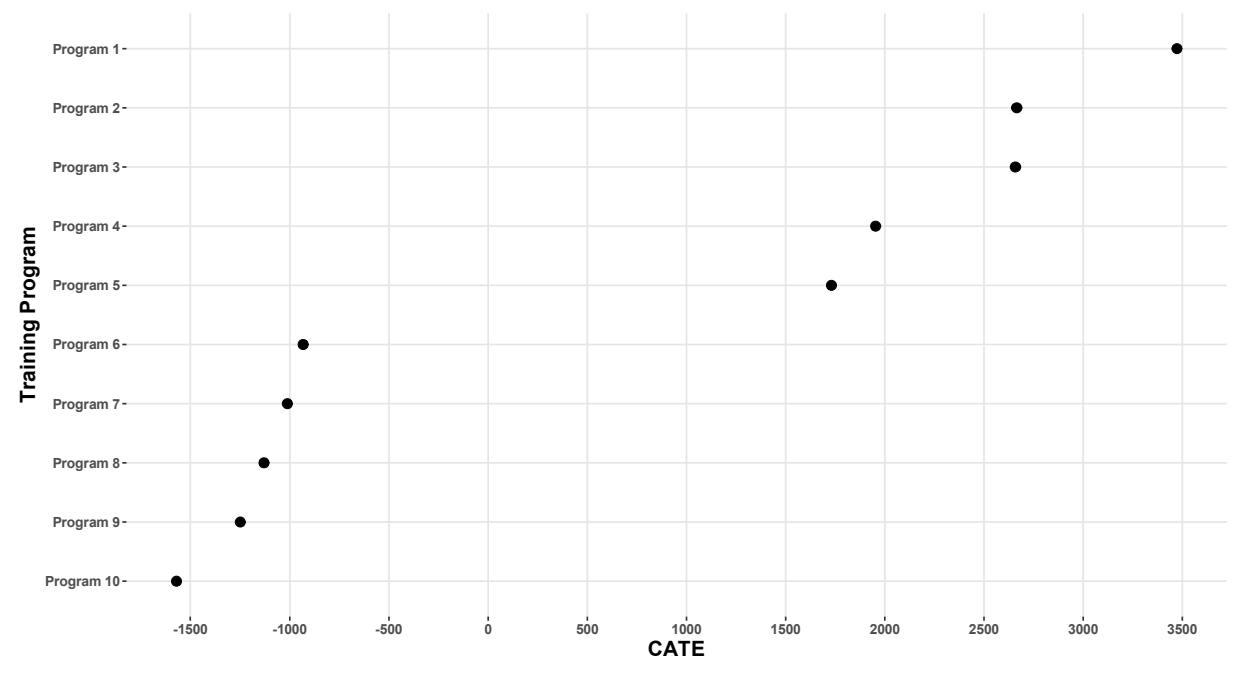

(B) Partnerships

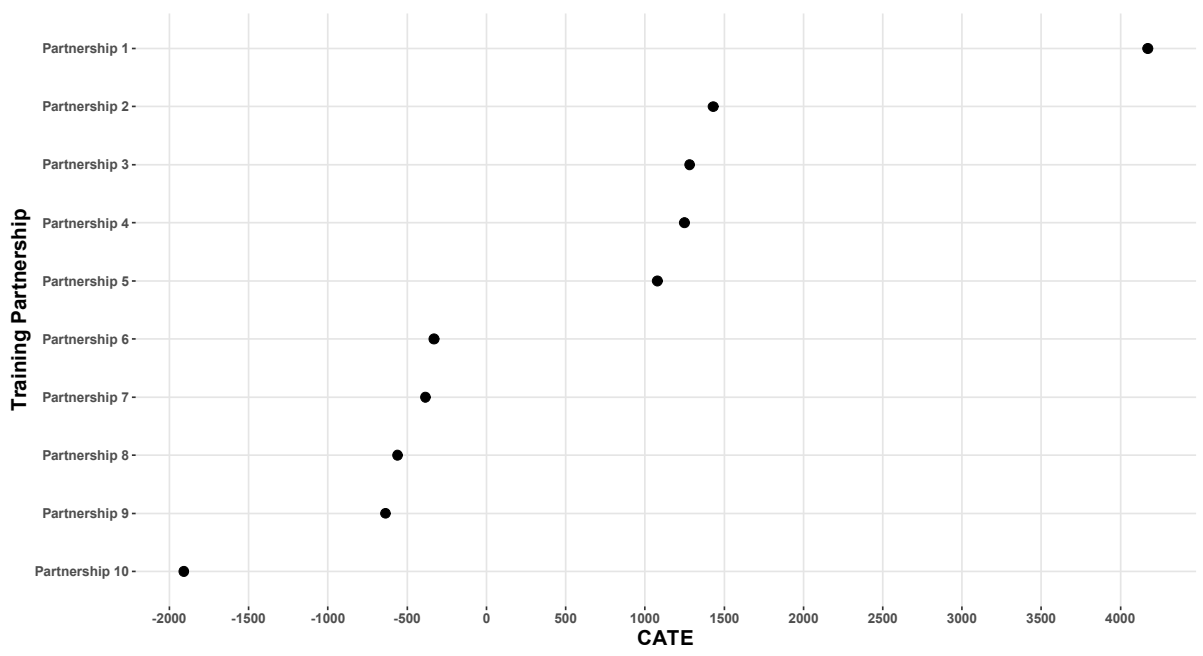

Figure 2: Heterogeneous Treatment Effects: Panel A shows the conditional average treatment effect for the highest and lowest Real Jobs RI programs based on the estimate value-added to wages; Panel B shows the highest and lowest value-added partnerships. Across all programs, the estimated valued-added return to Real Jobs RI programs is $\$ 605$.

As shown in Figure 1, it appears that, compared to their counterparts, participants in Real Jobs RI experience sustained wage boosts across the four quarters following enrollment. The graph shows that mean quarterly wages between the treatment and matched control groups are essentially the same in the four quarters $(-4$ to -1$)$ prior to training. Treated individuals (indicated by the dashed lines in the figure) enroll in training between quarters -1 and 1 . Earnings in quarters 2 to 4 occur post-training, and the mean divergence in post-training earnings is attributed as the causal value-added to earnings of Real Jobs RI enrollment. 


\subsection{DML estimates of value added}

Turning to our DML approach to causal inference, our first stage in the estimation method includes the propensity model (Equation 1) and outcome model (Equation 2). Our propensity model, fit with a Random Forest, yields an area under the receiver operating characteristic (AUROC) measure of 0.80 . Appendix Figure 5 shows that the common support of propensity scores for training (treatment) and non-training (control) individuals covers much of the range between 0 and 1, suggesting that the propensity scores do not perfectly separate those who enrolled in the training program and, therefore, provides a promising context for comparing similar individuals across treatment/control groups. The outcome model, also fit with a Random Forest, explains more than $80 \%$ of the variance in future quarterly wages (R-Squared of 0.836). Appendix Figure 6 plots the relationship between the actual mean quarterly wages and our predicted estimate of quarterly wages, showing a linear relationship between the actual and predicted measures.

Using the predicted values from the first stage regressions, we calculate the residualized outcome and treatment values and estimate the model in Equation 3 for the average treatment on the treated (ATT) of Real Jobs RI training programs. We find that this pooled effect of Real Jobs RI across all training programs is an increase in quarterly earnings of $\$ 605$ with a $95 \%$ confidence interval of $\$ 462$ to $\$ 747$. This corresponds to a $7-11 \%$ increase in wages above what we would expect to have seen in the absence of Real Jobs RI enrollment.

While we estimate a positive overall effect for Real Jobs RI, the value-added measures varied by partnership/program. The DML framework allows us to estimate the heterogenous treatment effect of each partnership/program. Figure 2 shows the conditional average treatment effects for the five top-performing and bottom-performing training programs and partnerships (panels A and B, respectively). These estimates are on a similar scale for both levels, ranging from the highest program estimate of $\$ 3470$ in quarterly earnings and highest partnership estimate of $\$ 4170$ to the lowest program estimate of $-\$ 1570$ and lowest partnership estimate of $-\$ 1910$.

\subsection{Conjoint analysis}

Table 2 summarizes information about the sample of respondents that completed the survey. A significant share of our sample was unemployed due to our sampling strategy but also due to the impact of the COVID-19 economic shutdown on individuals in households with below-median income. At the time of the survey, $53.7 \%$ of the survey sample was unemployed, and $46.3 \%$ were employed (32.8\% full-time and $13.5 \%$ part-time). Students, retirees, and those unemployed but not seeking employment were not surveyed. In addition, $60 \%$ of respondents were female and the mean age of respondents was just under 43 years. Two-thirds of survey respondents were non-white with $16 \%$ of respondents identifying as Black.

We asked survey respondents about their experience and interest in types of workforce training. Among survey respondents, $27.2 \%$ (548 respondents) had previously enrolled in a job training program. In addition, $90 \%$ of those who had enrolled in a training program reported completing the training. The most common types of job training programs that respondents had taken were computer and information sciences (20.6\%), health services (19.9\%), and business management and marketing $(17.7 \%)$. Respondents who expressed interest in job training programs were most likely to say that they were interested in courses related to computer and information sciences (30.7\%), business management and marketing (30.7\%), and health services (19.3\%). Of the respondents who had never enrolled in a job training program, the leading reasons for not enrolling included: "They are too expensive" (51.2\%) and "I am not sure if it would result in a better job, career, or skills" (48.5\%).

Of those who had never enrolled in job training, $74.8 \%$ of respondents said they would hope that the training would lead to a job with better wages or higher potential earnings. When choosing a training program, cost-benefit in monetary 
terms was most important; program cost, length, employment probability, and expected earnings are prominently important. When asked, "Which of the following pieces of information would you want to see about each training program to feel confident you will be able to choose the program that is best for you?", the leading factor was the total (net) cost of enrolling in the training program (64.6\% of respondents).

Table 3 shows the estimated demand elasticity for training programs for each information feature and how they vary by conjoint design model. We see that demand is near unit-elastic to cost: as program cost increases by one percent, demand decreases by slightly less than one percent. In Model 1, when only information on cost, duration, and location are available, demand is negatively impacted by all three. When completion rate is available, demand is positively responsive to completion rate; namely, we estimate that a one percent increase in the completion rate results in a 0.74 percent increase in demand for the training program. With the inclusion of a completion rate, program duration becomes less important as there is now a proxy for potential outcomes. Once earnings gains are added (Model 3), the importance of program duration and completion rate fall. In contrast, demand is very elastic (elasticity $>1$ ) to earnings gains.

Table 2: Summary statistics for survey respondents

\begin{tabular}{|c|c|}
\hline Variable & $\operatorname{Mean}(\mathrm{SD})$ \\
\hline Female & $0.60(0.49)$ \\
\hline Age & $42.7(13.4)$ \\
\hline White, Non-Hispanic & $0.66(0.48)$ \\
\hline Black & $0.16(0.37)$ \\
\hline Asian & $0.03(0.17)$ \\
\hline Hispanic & $0.15(0.36)$ \\
\hline Employed (Full Time) & $0.33(0.47)$ \\
\hline Unemployed (looking for work) & $0.54(0.50)$ \\
\hline \multirow[t]{2}{*}{ Ever enrolled in job training } & $0.27(0.45)$ \\
\hline & Count $(\%)$ \\
\hline \multicolumn{2}{|l|}{ Annual Income } \\
\hline$\$ 10,000$ or less & $396(19.7 \%)$ \\
\hline Between $\$ 10,001$ and $\$ 20,000$ & $286(14.2 \%)$ \\
\hline Between $\$ 20,001$ and $\$ 30,000$ & $377(18.7 \%)$ \\
\hline Between $\$ 30,001$ and $\$ 45,000$ & $354(17.6 \%)$ \\
\hline Between $\$ 45,001$ and $\$ 60,000$ & $378(18.8 \%)$ \\
\hline Between $\$ 60,001$ and $\$ 75,000$ & $223(11.1 \%)$ \\
\hline \multicolumn{2}{|l|}{ Region } \\
\hline Northeast & $435(21.6 \%)$ \\
\hline Midwest & $428(21.3 \%)$ \\
\hline South & $722(35.8 \%)$ \\
\hline West & $429(21.3 \%)$ \\
\hline Total Respondents & 2,014 \\
\hline
\end{tabular}


Table 3: Demand elasticities for training program information

\begin{tabular}{|c|c|c|c|c|c|c|}
\hline Training Program Feature & Model 1 & Model 2 & Model 3 & Model 4 & Model 5 & Model 6 \\
\hline \multirow[t]{2}{*}{ Cost (\$) } & $-0.815^{* * *}$ & $-0.900^{* * *}$ & $-0.838^{* * *}$ & $-0.669^{* * *}$ & $-0.511^{* * *}$ & $-0.657^{* * *}$ \\
\hline & $(0.036)$ & $(0.034)$ & $(0.035)$ & $(0.025)$ & $(0.025)$ & $(0.024)$ \\
\hline \multirow[t]{2}{*}{ Duration (Weeks) } & $-0.137^{* * *}$ & $-0.077^{* *}$ & -0.033 & $-0.083^{* *}$ & -0.001 & -0.041 \\
\hline & $(0.026)$ & $(0.027)$ & $(0.027)$ & $(0.027)$ & $(0.024)$ & $(0.027)$ \\
\hline \multirow[t]{2}{*}{ Travel Time (Minutes) } & $-0.071^{* *}$ & $-0.218^{* * *}$ & $-0.175^{* * *}$ & $-0.155^{* * *}$ & $-0.114^{* * *}$ & $-0.101^{* * *}$ \\
\hline & $(0.025)$ & $(0.027)$ & $(0.027)$ & $(0.029)$ & $(0.025)$ & $(0.027)$ \\
\hline \multirow[t]{2}{*}{ Completion Rate (\%) } & NA & $0.735^{* * *}$ & $0.514^{* * *}$ & NA & NA & NA \\
\hline & & $(0.038)$ & $(0.038)$ & & & \\
\hline \multirow[t]{2}{*}{ Expected Earnings (Post-training) } & NA & NA & $1.741^{* * *}$ & $1.736^{* * *}$ & NA & $1.319^{* * *}$ \\
\hline & & & $(0.156)$ & $(0.144)$ & & $(0.144)$ \\
\hline \multirow[t]{2}{*}{ Expected Earnings (No Training) } & NA & NA & NA & $-0.823^{* * *}$ & NA & NA \\
\hline & & & & $(0.145)$ & & \\
\hline \multirow[t]{2}{*}{ Expected Earnings Increase (\%) } & NA & NA & NA & NA & $0.408^{* * *}$ & NA \\
\hline & & & & & $(0.022)$ & \\
\hline \multirow[t]{2}{*}{ Expected Unemployment Rate } & NA & NA & NA & NA & NA & $-0.270^{* * *}$ \\
\hline & & & & & & $(0.023)$ \\
\hline Choice Options & 18,126 & 18,126 & 17,234 & 16,412 & 18,126 & 17,208 \\
\hline Respondents & 2,014 & 2,014 & 2,006 & 1,993 & 2,014 & 2,007 \\
\hline$\%$ said they would enroll in first choice program & $47.7 \%$ & $39.4 \%$ & $39.9 \%$ & $35.1 \%$ & $34.7 \%$ & $36.8 \%$ \\
\hline $\begin{array}{l}\text { Notes: Standard errors clusters by respondent re } \\
\text { Elasticities represent the estimated percentage } \\
\text { increases by } 1 \% \text {. NA indicates that an informatio }\end{array}$ & $\begin{array}{l}\text { ted in par } \\
\text { ge in the } \\
\text { ature wa }\end{array}$ & $\begin{array}{l}\text { es. Statis } \\
\text { of individ } \\
\text { ncluded } i\end{array}$ & $\begin{array}{l}\text { significa } \\
\text { loosing a } \\
\text { onjoint } f\end{array}$ & $\begin{array}{l}\text { th the }{ }^{* *}<0 \\
\text { ogram when } \\
\text { given mode }\end{array}$ & $\begin{array}{l}.001,{ }^{* *}<0 . \\
n \text { the featu }\end{array}$ & $\begin{array}{l}{ }^{*}<0.05 \text { level. } \\
\text { characteristi }\end{array}$ \\
\hline
\end{tabular}

Demand is most elastic to earnings and earnings increase, and the size of this elasticity indicates that this information will be a powerful driver of workers' choices and demand for training programs. The results also show that failing to provide earnings returns information leaves important needs unmet in the market and may cause workers to focus too much on poor proxies for labor market impact such as program duration and program completion rate.

Additional results show that these findings hold for individuals from all backgrounds (results for female respondents presented in Appendix Table 2 and male respondents in Appendix Table 3). However, we also found that overall, the lowest income and least educated workers (those earning less than or equal to $\$ 10,000$ per year and without a high school degree) are less sensitive to all types of information (See Appendix Table 4). This indicates that they will benefit 
from information distributed through job counselors, reinforcing the importance of collaborating with career center job counselors and non-profits to ensure they understand and effectively employ the earnings information to support informed decisions for the lowest-income workers.

\section{DISCUSSION}

Our nationwide survey results demonstrate the demand for information on value-added returns for workforce training programs among potential enrollees. We demonstrate how this information is present in existing administrative wage records and training program enrollment data, which can be combined with causal machine learning to estimate returns for training programs, both on average and per individual training program. The Rhode Island Department of Labor and Training has incorporated ROI measures based on our method into monthly status meetings that evaluate on-going Real Jobs RI partnerships and programs. Additionally, these ROI measures were presented as evidence to the Rhode Island General Assembly in 2020 during budgetary planning for Real Jobs RI. In continuing work, we are partnering with additional states to apply these value-added metrics to training and educational programs and publicize the metrics for jobseekers and training providers through a web and mobile application.

A key difference between our study and prior evaluations of federally-funded training under the Workforce Investment Act (WIA) is that our data include wage records for all workers, allowing us to construct estimates of the value added to training enrollees' future wages relative to a control population of similar workers who did not enroll in training. The two studies most like ours use WIA enrollment records linked to wage records in California [14] and Virginia [15] to calculate ROI as longer-term wage outcomes (2.5 to 5 years) relative to federal program costs. These results are presented as the percent return [14] or dollar-to-dollar return [15] relative to costs, which cannot be directly compared to our estimates of value-added returns to quarterly wages one year after enrollment. However, both prior studies find a positive average effect of training programs, which is consistent with our finding of a positive average treatment effect for Real Jobs RI. We cannot compare estimates of program-level effects since the prior studies do not estimate ROI at the program level.

Value-added returns are important for novel policy approaches such as outcomes-based financing. Outcomes-based financing, sometimes also called "Pay for Success" [37], is an investment vehicle designed to allow government to understand which programs measurably and meaningfully outcomes for their communities. In partnership with government, private funders provide financing-such as working capital loans-to service providers to implement community programs in health, education, or other human services. Funding is tied to measurable goals that are regularly evaluated with data. These goals are often additionally tied to cost-saving measures for government. For example, a workforce development program may be successful if it helps enrollees realize strong earnings gains a year after enrollment, thus reducing Unemployment Insurance costs for the state. If outcomes are met, then government pays the investor back with interest. If they are not met, government does not pay the investor back, and the financing term ends. This model allows government to move towards an outcomes-based contracting model with service providers at low risk, paying only for results.

Causal estimates of value-added, like those we present in this paper, could serve as key ROI metrics for outcomesbased financing partnerships around workforce development and education programs. In this arrangement, state and local government would use the value-added estimates to identify training outcomes they want to achieve; procure contracts that pay based on results achieved, rather than services performed; and finance the contracts in partnership with mission-driven investors so that government dollars pay for training programs that work. For example, prior Pay for Success partnerships with government, such as the Massachusetts Pathways to Economic Advancement, created a 
Pay for Success initiative that supported workforce development for refugees and immigrants with limited English skills [38]. The program trained 1,800 participants with success in terms of program completion, job placement, and increased earnings by $\$ 7,100$ two years after project enrollment. In addition, with up to $15 \%$ of all state WIOA funds expressly permitted for Pay for Success contracts [39], state and local partners may be able to put combine private investment funds with federal dollars to obtain higher impact and success in preparing American workers for the future of work.

More broadly, the national talent ecosystem needs accurate measures of workforce training programs' impact on labor force outcomes to function more efficiently. When used by workers and job counselors to select training and reskilling programs, these measures will create correct incentives for training providers to innovate and add more value, preparing workers from diverse backgrounds for in-demand jobs. The value-added measures we propose in this paper are a first step toward catalyzing a more effective reskilling market.

\section{ACKNOWLEDGMENTS}

We thank Niall Keleher, Octavio Medina, and Matt Darling for earlier contributions to the design of the study and the analysis. Parts of this work were supported by National Science Foundation Convergence Accelerator (1937061) and RAPID (2029746) awards to Justine S. Hastings.

\section{REFERENCES}

[1] Congressional Budget Office. 2012. Unemployment Insurance in the Wake of the Recent Recession. Retrieved August 20, 2021 from https://www.cbo.gov/publication/43734

[2] U.S. Department of Labor. 2019. WIOA Title I and III Annual Report Data: Program Year 2019. Retrieved September 22. 2021 from https://www.dol.gov/agencies/eta/performance/results

[3] Korn Ferry. 2018. Future of Work: The Global Talent Crunch. Retrieved October 22, 2021 from https://www.kornferry.com/content/dam/kornferry/docs/pdfs/KF-Future-of-Work-Talent-Crunch-Report.pdf

[4] James Manyika, Susan Lund, Michael Chui, Jacques Bughin, Jonathan Woetzel, Parul Batra, Ryan Ko, and Saurabh Sanghvi. 2017. Jobs Lost, Jobs Gained: Workforce Transitions in a Time of Automation. McKinsey Global Institute (November 28, 2017). Retrieved August 20, 2021 from https://www.mckinsey.com/featured-insights/future-of-work/jobs-lost-jobs-gained-what-the-future-of-work-will-mean-for-jobs-skills-and-wages

[5] David H. Autor. 2014. Skills, education, and the rise of earnings inequality among the 'other 99 percent.' Science 344, 6186 (May 2014 ), $843-851$. https://doi.org/10.1126/science.1251868

[6] David H. Autor, Alan Manning, and Christopher L. Smith. 2016. The Contribution of the Minimum Wage to US Wage Inequality over Three Decades: A Reassessment. American Economic fournal: Applied Economics 8, 1 (Jan. 2016), 58-99. https://doi.org/10.1257/app.20140073

[7] Andreas Hornstein, Per Krusell, and Giovanni L. Violante. 2005. The Effects of Technical Change on Labor Market Inequalities. In Handbook of Economic Growth, Vol. 1, Elsevier, 1275-1370. https://doi.org/10.1016/S1574-0684(05)01020-8

[8] Daron Acemoglu and David Autor. 2011. Skills, Tasks and Technologies: Implications for Employment and Earnings. In Handbook of Labor Economics, Vol. 4, Elsevier, 1043-1171. https://doi.org/10.1016/S0169-7218(11)02410-5

[9] White House Council of Economic Advisers. 2018. "Addressing America's Reskilling Challenge." Retrieved September 22, 2021 from https://trumpwhitehouse.archives.gov/briefings-statements/cea-report-addressing-americas-reskilling-challenge/

[10] Martha Laboissiere and Mona Mourshed. 2017. "Closing the skills gap: Creating workforce-development programs that work for everyone." McKinsey \& Company. Retrieved February 14, 2022 from: https://www.mckinsey.com/industries/education/our-insights/closing-the-skills-gapcreating-workforce-development-programs-that-work-for-everyone

[11] Zaber, Melanie, Lynn Karoly, and Katie Whipkey. 2019. "Reimagining the Workforce Development and Employment System for the 21st Century and Beyond." RAND Corporation, Research Report RR-2768-RC. https://doi.org/10.7249/RR2768

[12] Asher Wolinsky. 1983. Prices as Signals of Product Quality. The Review of Economic Studies 50, 4 (Oct. 1983), 647-658. https://doi.org/10.2307/2297767

[13] Burt S. Barnow and Jeffrey A. Smith. 2015. Employment and Training Programs. NBER Working Paper No. 21659. https://www.nber.org/papers/w21659

[14] Adrian R. Fleissig. 2014. Return on Investment from Training Programs and Intensive Services. Atlantic Economic fournal 42, (Jan. 2014 ), 39-51. https://doi.org/10.1007/s11293-013-9394-y

[15] Elsie Harper-Anderson. 2018. What Is the Return on Investment for Public Workforce Programs? An Analysis of WIA and TAA in Virginia. State and Local Government Review 50, 4 (Dec. 2018), 244-258. https://doi.org/10.1177/0160323X18823878

[16] Katherine P. Dickinson, Paul T. Decker, and Suzanne D. Kreutzer. 2002. Evaluation of WPRS Systems. In Targeting Employment Services, W.E. Upjohn Institute, Kalamazoo, MI, pp. 61-90. https://doi.org/10.17848/9781417524440.ch3 
[17] Dan A. Black, Jeffrey A. Smith, Mark C. Berger, and Brett J. Noel. 2003. Is the Threat of Reemployment Services More Effective Than the Services Themselves? Evidence from Random Assignment in the UI System. American Economic Review 93, 4 (Sep. 2003), $1313-1327$. https://doi.org/10.1257/000282803769206313

[18] Dan A. Black, Jose Galdo, and Jeffrey A. Smith. 2007. Evaluating Worker Profiling Using a Regression Discontinuity Approach. American Economic Review 97, 2 (May 2007), 104-107. https://doi.org/10.1257/aer.97.2.104

[19] Jacob Benus, Eileen Poe-Yamagata, Ying Wang, and Etan Blass. 2008. Reemployment and Eligibility Assessment (REA) Study: FY 2005 Initiative Final Report. IMPAQ International, Columbia, MD. Retrieved September 23, 2021 from https://wdr.doleta.gov/research/FullText_Documents/Reemployment $\% 20$ and $\% 20$ Eligibility $\% 20$ Assessment $\% 20 \% 28$ REA $\% 29 \% 20$ Study $\% 20$ Final $\% 20$ Re port\%20March\%202008.pdf

[20] Eileen Poe-Yamagata, Jacob Benus, Nicholas Bill, Hugh Carrington, Marios Michaelides, and Ted Shen. 2011. Impact of the Reemployment and Eligibility Assessment (REA) Initiative. IMPAQ International, Columbia, MD. Retrieved September 23, 2021 from https://wdr.doleta.gov/research/FullText_Documents/ETAOP_2012_08_Impact_of the_REA_Initiative.pdf

[21] Marios Michaelides, Eileen Poe-Yamagata, Jacob Benus, and Dharmendra Tirumalasetti. 2021. Impact of the Reemployment and Eligibility Assessment (REA) Initiative in Nevada. IMPAQ International, Columbia, MD. Retrieved September 23, 2021 from https://wdr.doleta.gov/research/FullText_Documents/ETAOP_2012_08_REA_Nevada_Follow_up_Report.pdf

[22] Dayanand S. Manoli, Marios Michaelides, and Ankur Patel. 2018. Long-Term Effects of Job-Search Assistance: Experimental Evidence Using Administrative Tax Data. NBER Working Paper No. 24422. https://www.nber.org/papers/w224422

[23] Robert J. LaLonde. 1986. Evaluating the Econometric Evaluations of Training Programs with Experimental Data. American Economic Review 76, 4 (Sep. 1986), 604-620. https://www.jstor.org/stable/1806062

[24] Kenneth A. Couch. 1992. New Evidence on the Long-Term Effects of Employment Training Programs. Fournal of Labor Economics 10, 4 (Oct. 1992), 380-88.

[25] Robert J. LaLonde. 2003. Employment and Training Programs. In Means-Tested Transfer Programs in the United States, University of Chicago Press, Chicago, IL, 517-585. http://www.nber.org/chapters/c10261

[26] Shanna Pearson-Merkowitz, Skye Leedahl, Aaron Ley, Bridget Hall, Kristin Sodhi, and Marissa DeOliveira. 2018. Real Jobs Rhode Island: a detailed analysis for Rhode Island's Department of Labor and Training. Social Science Institute for Research, Education, and Policy, University of Rhode Island, Kingston, RI. Retrieved September 23, 2021 from https://web.uri.edu/ssirep/rjri-analysis/

[27] Rhode Island Department of Labor and Training. 2021. Real Jobs Rhode Island Impact Report: July 2021. Retrieved September 23, 2021 from https://dlt.ri.gov/documents/pdf/realjobs/ProgReportRJRI.pdf

[28] Alberto Abadie and Guido Imbens. 2002. Simple and Bias-Corrected Matching Estimators for Average Treatment Effects. NBER Working Paper No. 283. https://www.nber.org/papers/t0283

[29] Victor Chernozhukov, Denis Chetverikov, Mert Demirer, Esther Duflo, Christian Hansen, Whitney Newey, and James Robins. 2018. Double/debiased machine learning for treatment and structural parameters. The Econometrics fournal 21, 1 (Feb. 2018), C1-C68. https://doi.org/10.1111/ectj.12097

[30] Vira Semenova, Matt Goldman, Victor Chernozhukov, and Matt Taddy. 2017. Estimation and Inference on Heterogeneous Treatment Effects in HighDimensional Dynamic Panels. arXiv:1712.09988. Retrieved from https://arxiv.org/abs/1712.09988

[31] Jonah E. Rockoff. 2004. The Impact of Individual Teachers on Student Achievement: Evidence from Panel Data. American Economic Review 94, 2 (May 2004), 247-252. https://doi.org/10.1257/0002828041302244

[32] Thomas J. Kane and Douglas O. Staiger. 2008. Estimating Teacher Impacts on Student Achievement: An Experimental Evaluation. NBER Working Paper No. 14607. https://www.nber.org/papers/w14607

[33] Raj Chetty, John N. Friedman, and Jonah E. Rockoff. Measuring the Impacts of Teachers I: Evaluating Bias in Teacher Value-Added Estimates. American Economic Review 104, 9 (Sep. 2014), 2593-2632. https://doi.org/10.1257/aer.104.9.2593

[34] Harald Beyer, Justine S. Hastings, Christopher Neilson, and Seth Zimmerman. 2015. Connecting Student Loans to Labor Market Outcomes: Policy Lessons from Chile. American Economic Review 105, 5 (May 2015), 508-513. https://doi.org/10.1257/aer.p20151026.

[35] Bryan K. Orme. 2010. Getting Started with Conjoint Analysis: Strategies for Pricing Research (2nd ed.). Research Publishers, Madison, WI.

[36] Vithala R. Rao. 2014. Applied Conjoint Analysis. Springer Verlag. https://doi.org/10.1007/978-3-540-87753-0

[37] Nonprofit Finance Fund. 2019. A Comparative Analysis of the First 25 Pay for Success Projects in the United States. Retrieved September 24, 2021 from https://nff.org/file/752/download?token=wttj8BRC

[38] Mission Investors Exchange. 2018. Pay for Success in Action: Massachusetts Pathways to Economic Advancement. Retrieved September 24, 2021 from https://missioninvestors.org/resources/pay-success-action-massachusetts-pathways-economic-advancement

[39] Results for America. 2017. Funding What Works: Incorporating Pay for Success Language in Federal Legislation. Retrieved September 22, 2021 from https://results4america.org/tools/funding-works-incorporating-pay-success-language-federal-legislation/ 


\section{A APPENDICES}

Appendix Table 1: Content of conjoint models was randomly varied

\begin{tabular}{|c|c|c|c|c|c|c|}
\hline & $\begin{array}{l}\text { Model } 1 \\
\mathrm{~N}=18,126\end{array}$ & $\begin{array}{l}\text { Model } 2 \\
\mathrm{~N}=18,126\end{array}$ & $\begin{array}{l}\text { Model } 3 \\
\mathrm{~N}=18,126\end{array}$ & $\begin{array}{l}\text { Model } 4 \\
\mathrm{~N}=18,126\end{array}$ & $\begin{array}{l}\text { Model } 5 \\
\mathrm{~N}=18,126\end{array}$ & $\begin{array}{l}\text { Model } 6 \\
\mathrm{~N}=18,126\end{array}$ \\
\hline Cost & $\begin{array}{c}4521 \\
(5304)\end{array}$ & $\begin{array}{c}5278 \\
(5383)\end{array}$ & $\begin{array}{c}5291 \\
(5338)\end{array}$ & $\begin{array}{c}5683 \\
(5572)\end{array}$ & $\begin{array}{c}5314 \\
(5476)\end{array}$ & $\begin{array}{c}5677 \\
(5561)\end{array}$ \\
\hline Duration & $6.80(3.50)$ & $7.16(3.43)$ & $7.13(3.45)$ & $7.01(3.42)$ & $6.96(3.49)$ & $6.99(3.41)$ \\
\hline Travel Time & $32.8(18.0)$ & $34.6(17.0)$ & $35.2(17.0)$ & $35.0(17.1)$ & $34.8(17.0)$ & $35.0(17.1)$ \\
\hline Completion Rate & NA & $56.5(23.2)$ & $56.2(23.5)$ & NA & NA & NA \\
\hline $\begin{array}{l}\text { Typical Earnings of past enrollees, after training } \\
\text { (\% of baseline earnings) }\end{array}$ & NA & NA & $1.10(0.14)$ & $1.10(0.14)$ & NA & $1.10(0.14)$ \\
\hline $\begin{array}{l}\text { Typical Earnings of past enrollees, had they not } \\
\text { enrolled (\% of baseline earnings) }\end{array}$ & NA & NA & NA & $1.10(0.14)$ & NA & NA \\
\hline Percentage increase in earnings for past enrollees & NA & NA & NA & NA & $12.6(10.1)$ & NA \\
\hline Unemployment rate for past enrollees & NA & NA & NA & NA & NA & $12.5(8.52)$ \\
\hline
\end{tabular}


Appendix Table 2: Demand elasticities for training program information, female respondents

\begin{tabular}{|c|c|c|c|c|c|c|}
\hline Training Program Feature & Model 1 & Model 2 & Model 3 & Model 4 & Model 5 & Model 6 \\
\hline \multirow[t]{2}{*}{ Cost $(\$)$} & $-0.937^{* * *}$ & $-1.00^{\star * *}$ & $-0.883^{* * *}$ & $-0.691^{* * *}$ & $-0.518^{* * *}$ & $-0.702^{* * *}$ \\
\hline & $(0.053)$ & $(0.046)$ & $(0.033)$ & $(0.033)$ & $(0.033)$ & $(0.032)$ \\
\hline \multirow[t]{2}{*}{ Duration (Weeks) } & $-0.118^{* * *}$ & -0.064 & -0.039 & $-0.073^{*}$ & -0.143 & -0.016 \\
\hline & $(0.034)$ & $(0.034)$ & $(0.037)$ & $(0.030)$ & $(0.036)$ & $(0.035)$ \\
\hline \multirow[t]{2}{*}{ Travel Time (Minutes) } & $-0.095^{* *}$ & $-0.241^{* * *}$ & $-0.212^{* * *}$ & $-0.143^{* * *}$ & $-0.143^{* * *}$ & $-0.119^{* * *}$ \\
\hline & $(0.034)$ & $(0.036)$ & $(0.038)$ & $(0.036)$ & $(0.036)$ & $(0.036)$ \\
\hline \multirow[t]{2}{*}{ Completion Rate $(\%)$} & NA & $0.791^{* * \star}$ & $0.503^{* * *}$ & NA & NA & NA \\
\hline & & $(0.049)$ & $(0.049)$ & & & \\
\hline \multirow[t]{2}{*}{ Expected Earnings (Post-training) } & NA & NA & $1.861^{* * *}$ & $1.728^{* * *}$ & NA & $1.466^{* * *}$ \\
\hline & & & $(0.210)$ & $(0.191)$ & & $(0.191)$ \\
\hline \multirow[t]{2}{*}{ Expected Earnings (No Training) } & NA & NA & NA & $-0.908^{* * *}$ & NA & NA \\
\hline & & & & $(0.187)$ & & \\
\hline \multirow[t]{2}{*}{ Expected Earnings Increase (\%) } & NA & NA & NA & NA & $0.425^{* * *}$ & NA \\
\hline & & & & & $(0.029)$ & \\
\hline \multirow[t]{2}{*}{ Expected Unemployment Rate } & NA & NA & NA & NA & NA & $-0.302^{* * *}$ \\
\hline & & & & & & $(0.031)$ \\
\hline Choice Options & 10,953 & 10.953 & 10,355 & 9,810 & 10,953 & 10.354 \\
\hline Respondents & 1217 & 1217 & 1212 & 1202 & 1217 & 1212 \\
\hline$\%$ said they would enroll in first choice program & $47.1 \%$ & $38.6 \%$ & $38.4 \%$ & $33.1 \%$ & $32.5 \%$ & $35.0 \%$ \\
\hline $\begin{array}{l}\text { Notes: Standard errors clusters by respondent rep } \\
\text { Elasticities represent the estimated percentage ch } \\
\text { increases by } 1 \% \text {. NA indicates that an informatior }\end{array}$ & $\begin{array}{l}\text { in parent } \\
\text { in the sha } \\
\text { ure was } n\end{array}$ & $\begin{array}{l}\text { Statistica } \\
\text { individual } \\
\text { luded in th }\end{array}$ & $\begin{array}{l}\text { gnificant } \\
\text { osing a p } \\
\text { jjoint for }\end{array}$ & $\begin{array}{l}\text { e } e^{* * *}<0.00 \\
\text { am when } \\
\text { ven model }\end{array}$ & $\begin{array}{l}1,{ }^{* *}<0.01 \text {, } \\
\text { the feature }\end{array}$ & $\begin{array}{l}0.05 \text { level. } \\
\text { aracteristics }\end{array}$ \\
\hline
\end{tabular}


Appendix Table 3: Demand elasticities for training program information, male respondents

\begin{tabular}{|c|c|c|c|c|c|c|}
\hline Training Program Feature & Model 1 & Model 2 & Model 3 & Model 4 & Model 5 & Model 6 \\
\hline \multirow[t]{2}{*}{ Cost $(\$)$} & $-0.662^{* * *}$ & $-0.753^{* * *}$ & $-0.777^{* * *}$ & $-0.645^{* * *}$ & $-0.499^{* * *}$ & $-0.594^{* * *}$ \\
\hline & $(0.048)$ & $(0.054)$ & $(0.039)$ & $(0.039)$ & $(0.039)$ & $(0.035)$ \\
\hline \multirow[t]{2}{*}{ Duration (Weeks) } & $-0.167^{\star * *}$ & $-0.097^{\star}$ & -0.024 & $-0.095^{*}$ & -0.068 & -0.074 \\
\hline & $(0.042)$ & $(0.042)$ & $(0.043)$ & $(0.039)$ & $(0.045)$ & $(0.045)$ \\
\hline \multirow[t]{2}{*}{ Travel Time (Minutes) } & $-0.046^{* *}$ & $-0.180^{* * *}$ & $-0.126^{* * *}$ & $-0.178^{* * *}$ & $-0.084^{*}$ & -0.076 \\
\hline & $(0.038)$ & $(0.041)$ & $(0.045)$ & $(0.041)$ & $(0.041)$ & $(0.043)$ \\
\hline \multirow[t]{2}{*}{ Completion Rate $(\%)$} & NA & $0.666^{* * \star}$ & $0.528^{* * *}$ & NA & NA & NA \\
\hline & & $(0.059)$ & $(0.060)$ & & & \\
\hline \multirow[t]{2}{*}{ Expected Earnings (Post-training) } & NA & NA & $1.586^{* * *}$ & $1.768^{* * *}$ & NA & $1.119^{* * *}$ \\
\hline & & & $(0.233)$ & $(0.219)$ & & $(0.219)$ \\
\hline \multirow[t]{2}{*}{ Expected Earnings (No Training) } & NA & NA & NA & $-0.724^{* * *}$ & NA & NA \\
\hline & & & & $(0.231)$ & & \\
\hline \multirow[t]{2}{*}{ Expected Earnings Increase (\%) } & NA & NA & NA & NA & $0.388^{* * *}$ & NA \\
\hline & & & & & $(0.035)$ & \\
\hline \multirow[t]{2}{*}{ Expected Unemployment Rate } & NA & NA & NA & NA & NA & $-0.220^{* * *}$ \\
\hline & & & & & & $(0.034)$ \\
\hline Choice Options & 7119 & 7119 & 6827 & 6554 & 7119 & 6803 \\
\hline Respondents & 791 & 791 & 788 & 785 & 791 & 789 \\
\hline$\%$ said they would enroll in first choice program & $48.7 \%$ & $40.6 \%$ & $42.3 \%$ & $38.3 \%$ & $38.2 \%$ & $39.5 \%$ \\
\hline $\begin{array}{l}\text { Notes: Standard errors clusters by respondent rep } \\
\text { Elasticities represent the estimated percentage ch } \\
\text { increases by } 1 \% \text {. NA indicates that an informatior }\end{array}$ & $\begin{array}{l}\text { in parent } \\
\text { in the sha } \\
\text { ure was no }\end{array}$ & $\begin{array}{l}\text { Statistica } \\
\text { individual } \\
\text { luded in th }\end{array}$ & $\begin{array}{l}\text { gnificant } \\
\text { osing a p } \\
\text { jjoint for }\end{array}$ & $\begin{array}{l}\text { e } e^{* * *}<0.00 \\
\text { am when } \\
\text { ven model }\end{array}$ & $\begin{array}{l}1,{ }^{* *}<0.01 \text {, } \\
\text { the feature }\end{array}$ & $\begin{array}{l}0.05 \text { level. } \\
\text { aracteristics }\end{array}$ \\
\hline
\end{tabular}


Appendix Table 4: Demand elasticities for training program information, earnings at or below $\$ 10,000$ and high school degree or less

\begin{tabular}{|c|c|c|c|c|c|c|}
\hline Training Program Feature & Model 1 & Model 2 & Model 3 & Model 4 & Model 5 & Model 6 \\
\hline \multirow[t]{2}{*}{ Cost $(\$)$} & $-0.557^{* * *}$ & $-0.604^{* * *}$ & $-0.615^{* * *}$ & $-0.522^{* * *}$ & $-0.482^{* * *}$ & $-0.498^{* * *}$ \\
\hline & $(0.066)$ & $(0.088)$ & $(0.062)$ & $(0.067)$ & $(0.067)$ & $(0.055)$ \\
\hline \multirow[t]{2}{*}{ Duration (Weeks) } & $-0.120^{*}$ & -0.0107 & -0.087 & -0.116 & 0.039 & 0.060 \\
\hline & $(0.063)$ & $(0.062)$ & $(0.070)$ & $(0.078)$ & $(0.066)$ & $(0.074)$ \\
\hline \multirow[t]{2}{*}{ Travel Time (Minutes) } & -0.010 & -0.125 & -0.057 & -0.114 & -0.100 & -0.141 \\
\hline & $(0.062)$ & $(0.065)$ & $(0.073)$ & $(0.080)$ & $(0.064)$ & $(0.078)$ \\
\hline \multirow[t]{2}{*}{ Completion Rate (\%) } & NA & $0.440^{* * *}$ & $0.238^{* * *}$ & NA & NA & NA \\
\hline & & $(0.089)$ & $(0.102)$ & & & \\
\hline \multirow[t]{2}{*}{ Expected Earnings (Post-training) } & NA & NA & 0.706 & 0.790 & NA & $0.571^{*}$ \\
\hline & & & $(0.399)$ & $(0.432)$ & & $(0.427)$ \\
\hline \multirow[t]{2}{*}{ Expected Earnings (No Training) } & NA & NA & NA & -0.759 & NA & NA \\
\hline & & & & $(0.428)$ & & \\
\hline \multirow[t]{2}{*}{ Expected Earnings Increase (\%) } & NA & NA & NA & NA & $0.169^{* * *}$ & NA \\
\hline & & & & & $(0.051)$ & \\
\hline \multirow[t]{2}{*}{ Expected Unemployment Rate } & NA & NA & NA & NA & NA & $-0.168^{* * *}$ \\
\hline & & & & & & $(0.055)$ \\
\hline Choice Options & 2763 & 2763 & 2417 & 2133 & 2763 & 2405 \\
\hline Respondents & 307 & 307 & 303 & 295 & 307 & 304 \\
\hline$\%$ said they would enroll in first choice program & $42.5 \%$ & $35.3 \%$ & $34.6 \%$ & $33.0 \%$ & $32.7 \%$ & $32.1 \%$ \\
\hline $\begin{array}{l}\text { Notes: Standard errors clusters by respondent re } \\
\text { Elasticities represent the estimated percentage ch } \\
\text { increases by } 1 \% \text {. NA indicates that an information }\end{array}$ & $\begin{array}{l}\text { in parent } \\
\text { in the sha } \\
\text { ure was nc }\end{array}$ & $\begin{array}{l}\text { Statistic } \\
\text { individua } \\
\text { uded in } \mathrm{t}\end{array}$ & $\begin{array}{l}\text { ignificant } \\
\text { oosing a pr } \\
\text { njoint for }\end{array}$ & $\begin{array}{l}\text { e } e^{* * *}<0.00 \\
\text { am when } t \\
\text { ven model }\end{array}$ & $\begin{array}{l}1,{ }^{* *}<0.01 \text {, } \\
\text { the feature }\end{array}$ & $\begin{array}{l}0.05 \text { level. } \\
\text { aracteristic }\end{array}$ \\
\hline
\end{tabular}




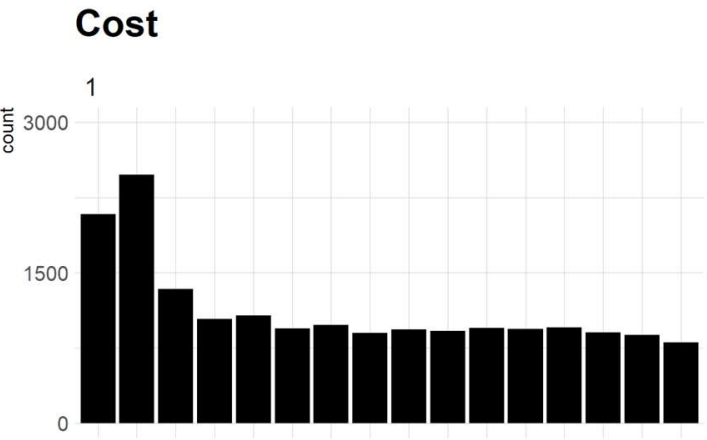

2

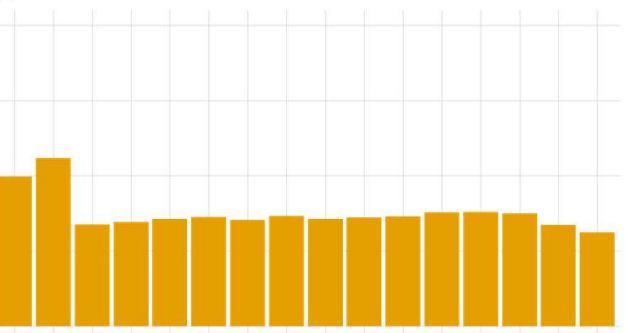

3
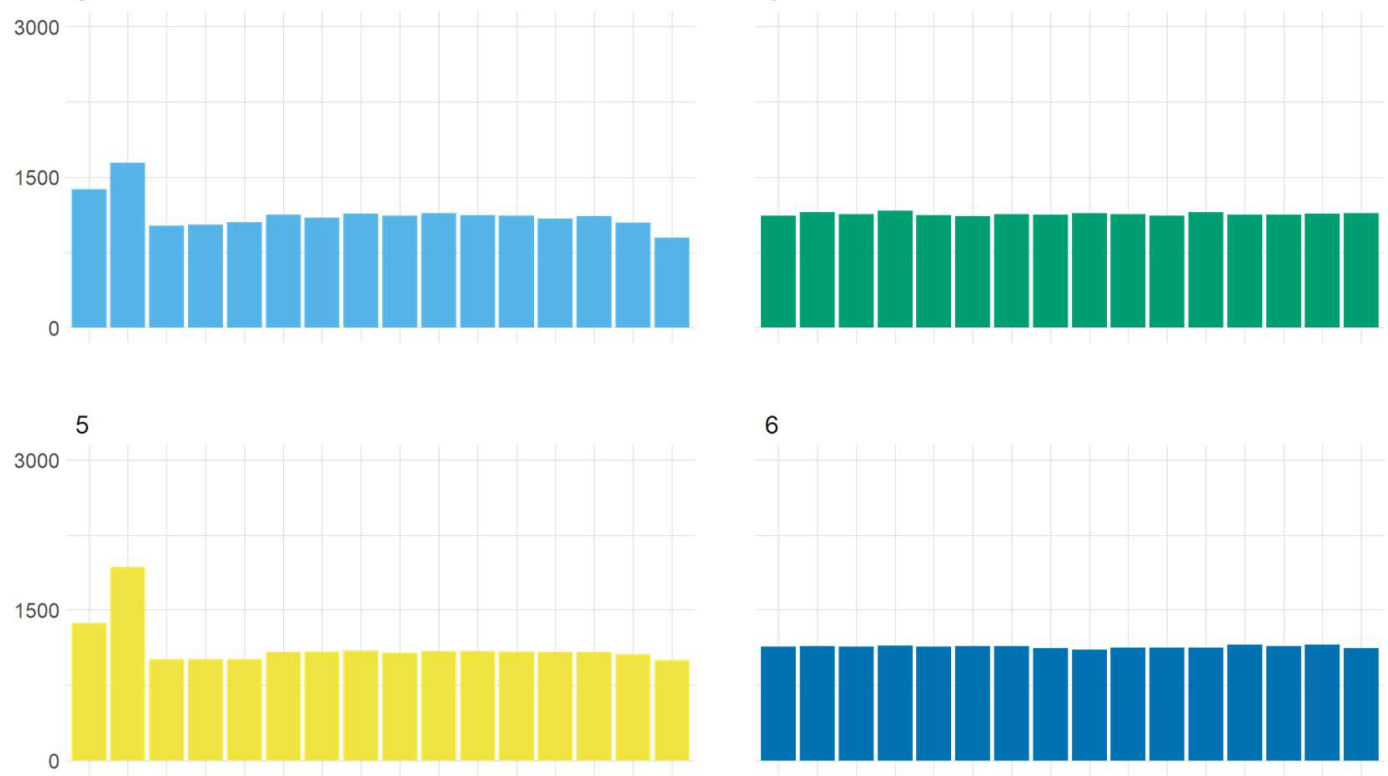

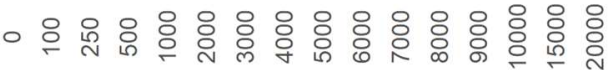

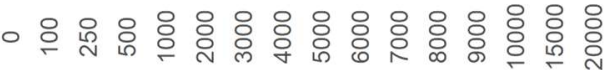

Cost (USD)

Appendix Figure 1: Distribution of training program cost, by conjoint model 


\section{Duration of Training Program}

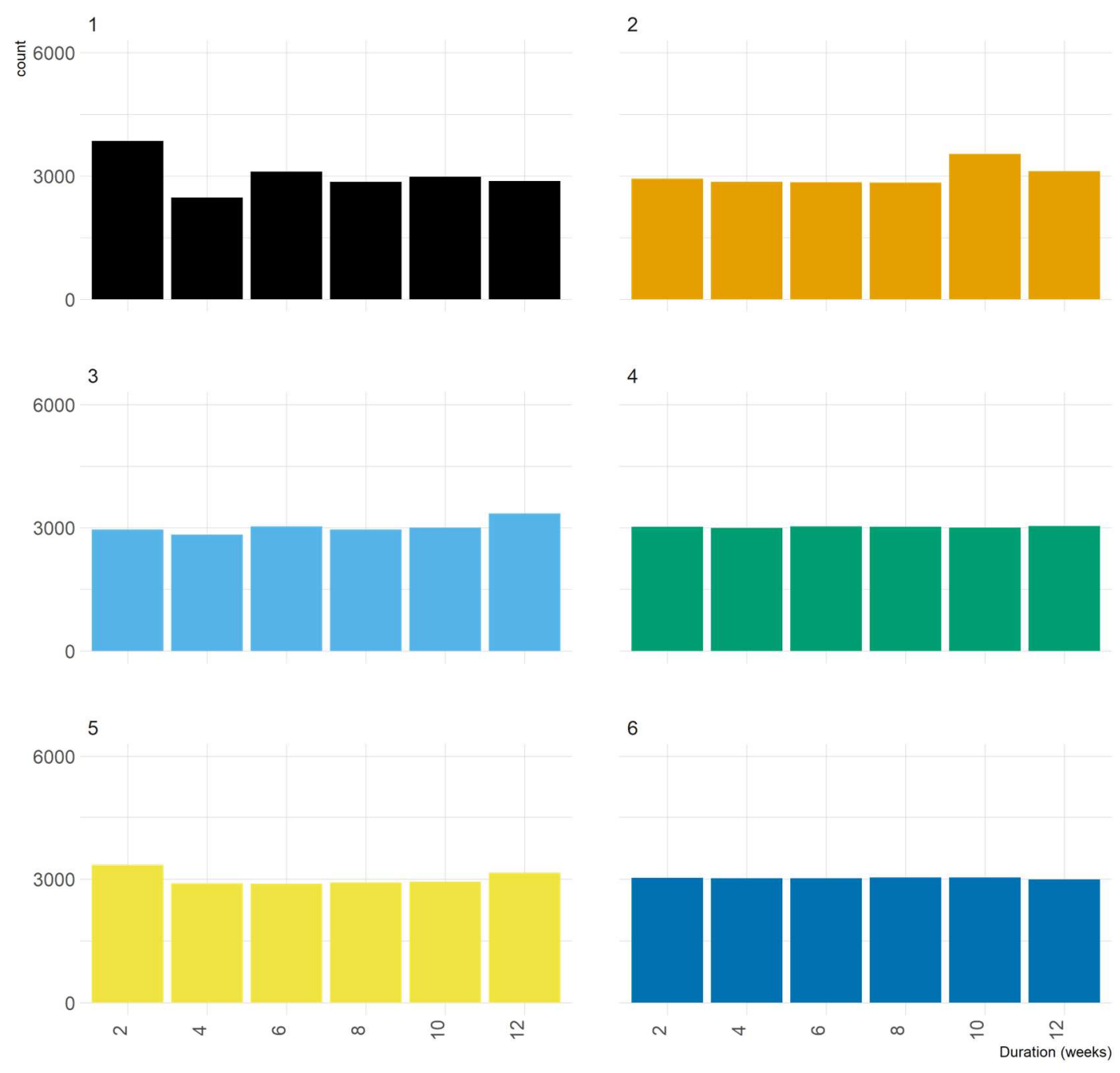

Appendix Figure 2: Distribution of training program duration, by conjoint model 
Travel Time

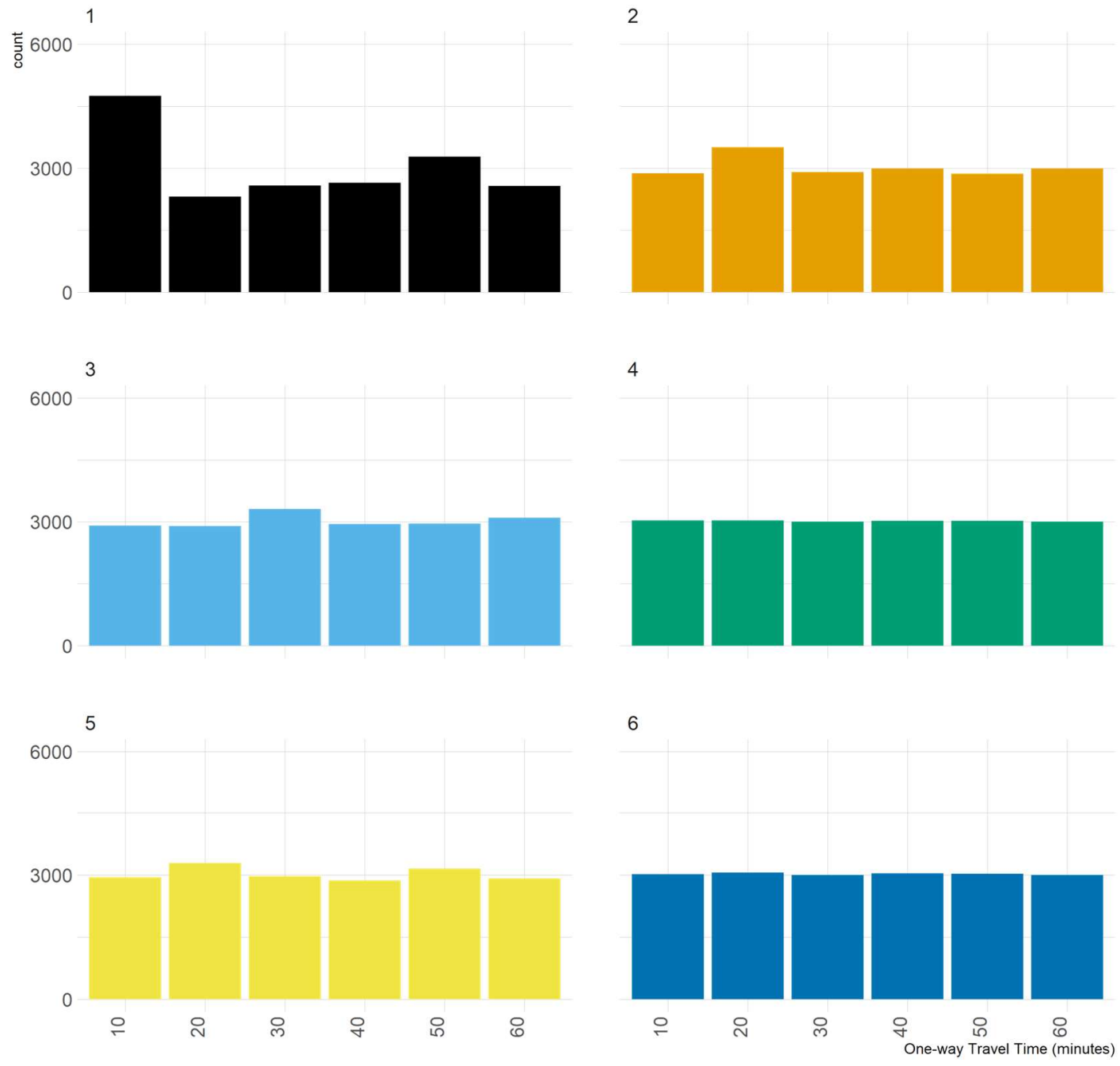

Appendix Figure 3: Distribution of travel time to training, by conjoint model 


\section{Post-Training Earnings}

by Conjoint Table and Reference Period

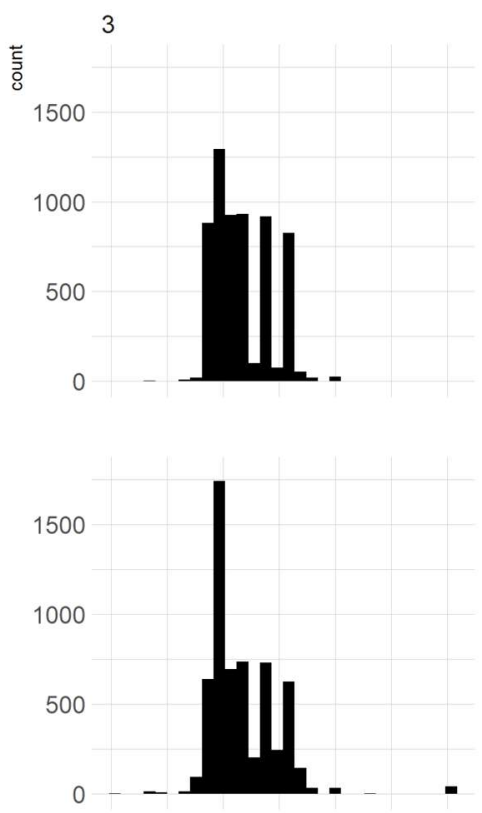

4
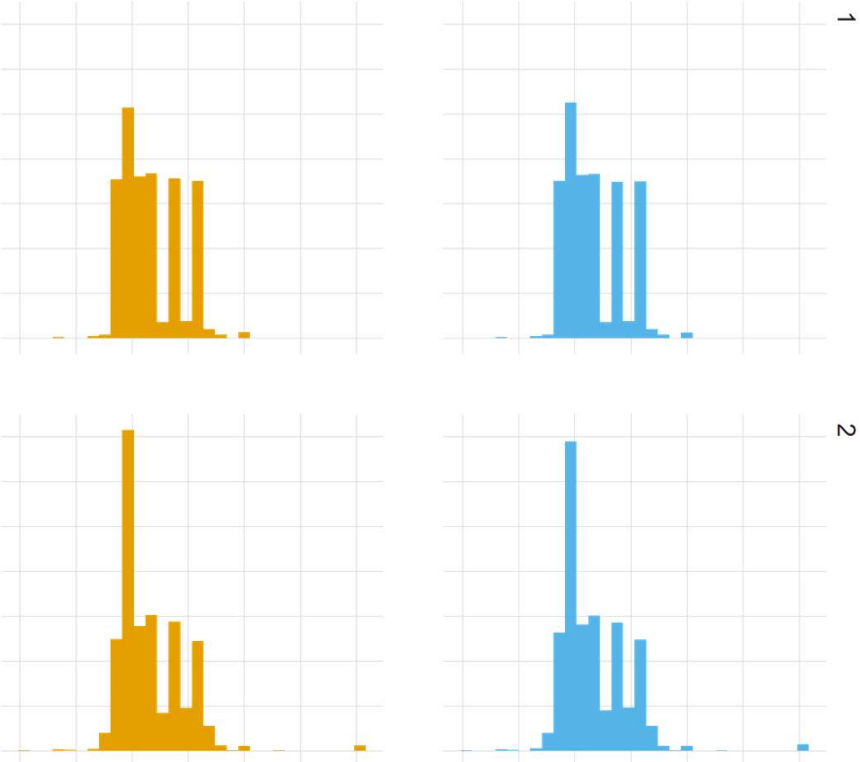

6

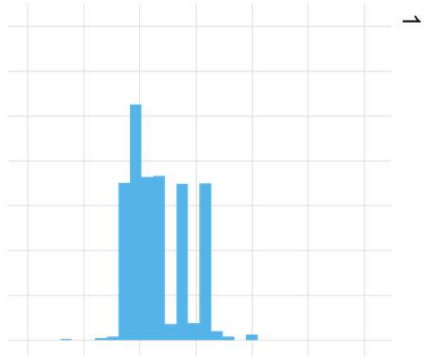

N

$\omega$
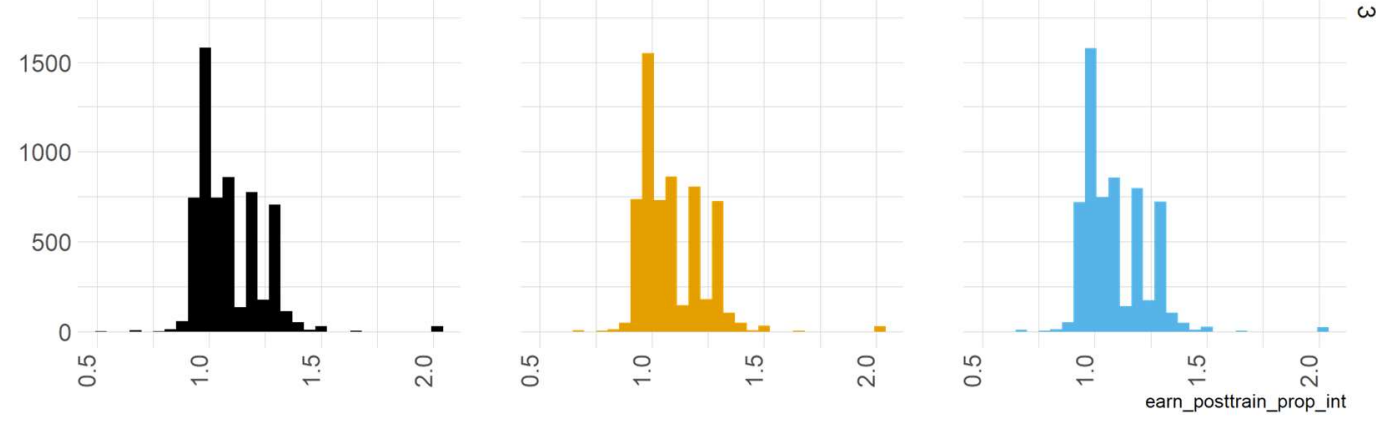

Appendix Figure 4: Distribution of expected post-training earnings, by conjoint model and earnings period 


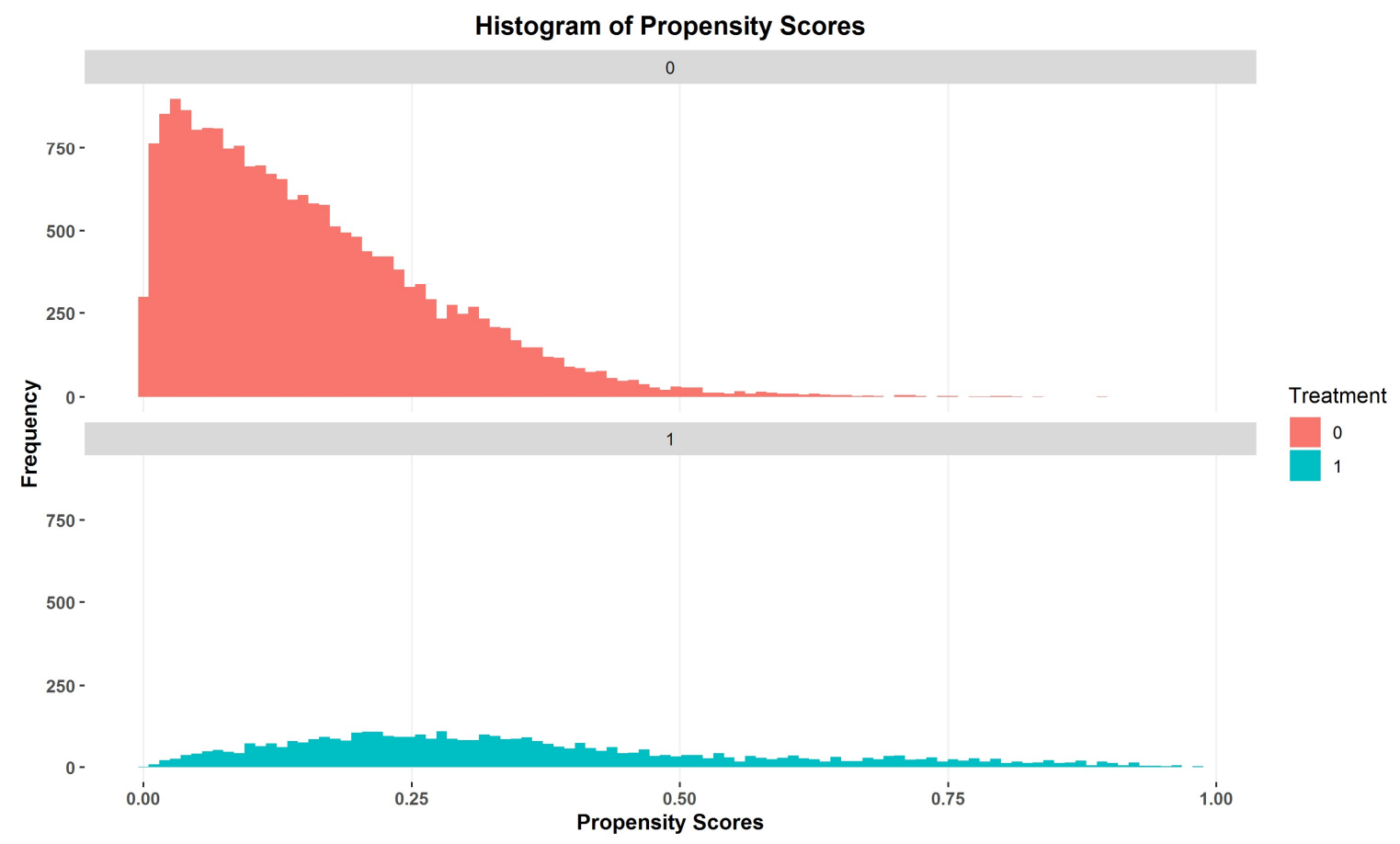

Appendix Figure 5: Propensity scores from first stage prediction of training program enrollment (Equation 1). 


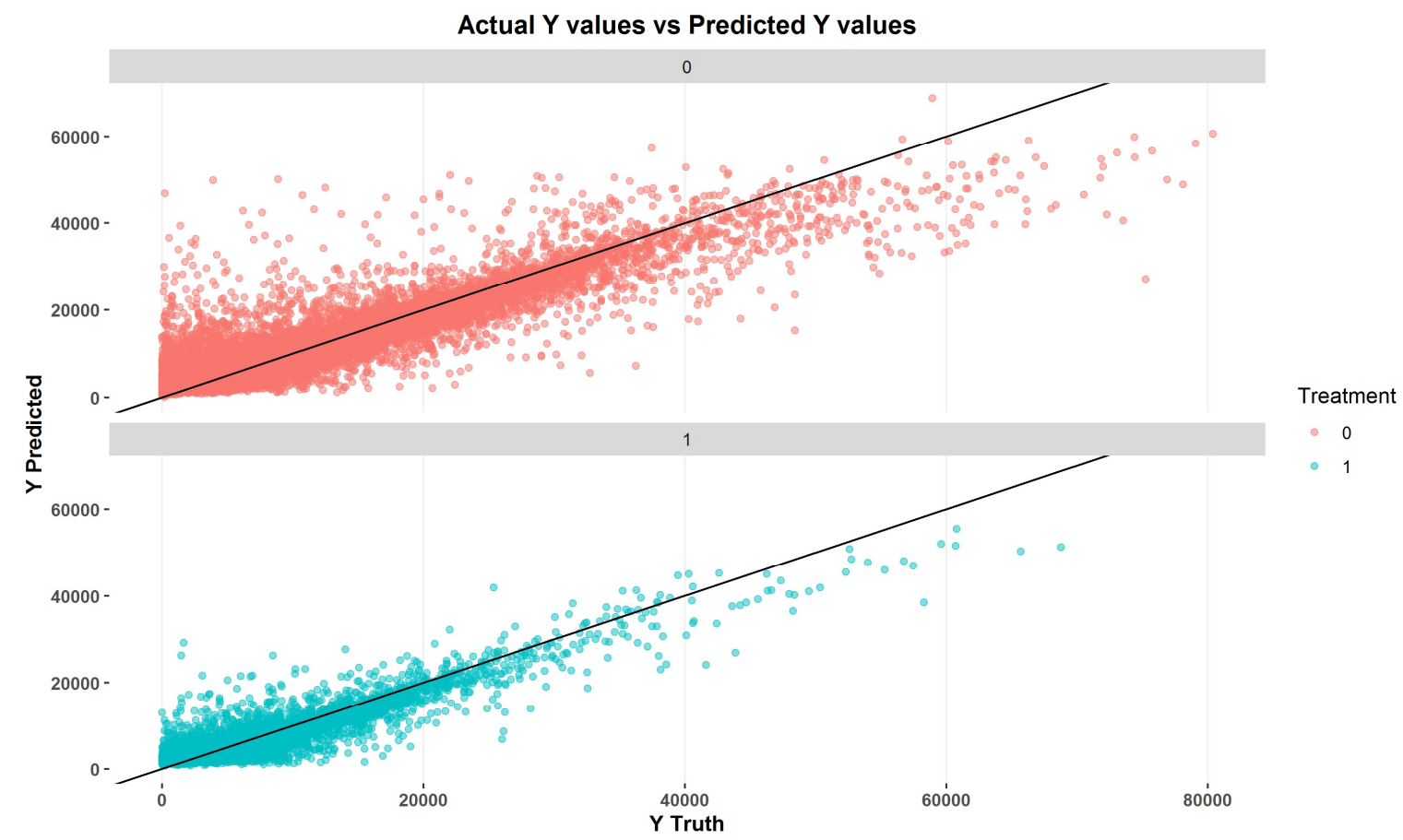

Appendix Figure 6: Predicted versus actual outcomes in the outcome model (Equation 2). 


\section{A.1 Survey design}

We designed the survey for the nationwide conjoint study by sourcing questions from well-established, existing surveys, where possible. Below, we provide the full text of each survey question along with detailed notes about the source, if it came from an existing survey, or about how we designed the question if it did not.

\section{A.1.1 Screening Questions}

To be eligible for the survey, respondents must be over the age of 18 , earn less than $\$ 75,000$ and either be unemployed $(\mathrm{S} 8=3,4,5)$ or employed and have filed for Unemployment Insurance in the last three years $(\mathrm{S} 10=1)$. They must also not be students $(\mathrm{S} 7=4)$.

S1 What is your gender?

Female.

Male.

Other:

S2 In what month and year were you born?

S3 In which state do you live for most of the year?

S4 Are you of Hispanic, Latino, or Spanish origin?

No, not of Hispanic, Latino, or Spanish origin. 1

Yes. 2

S5 What is your race? Select all that apply.

White (e.g. German, Irish, English, Italian, Lebanese, Egyptian, etc.). 1

Black or African American (e.g. African American, Jamaican, Haitian, Nigerian,

Ethiopian, Somali, etc.). 2

American Indian or Alaska Native (e.g. Navajo Nation, Blackfeet Tribe, Mayan, Aztec, Native Village of Barrow Inupiat Traditional Government, Nome Eskimo Community, etc.). 3

Asian (Chinese, Filipino, Indian, Pakistani, Cambodian, Hmong, Vietnamese, Korean, Japanese, etc.). 4

Pacific Islander or Native Hawaiian (e.g. Native Hawaiian, Samoan, Chamorro, Tongan, Fijian, Marshallese, etc.). 5

Other:

S6 What is the highest degree or level of school you have completed? Select one only. Elementary school or less. 1

Middle school. 2

High school. 3

Some college. 4

Associate's degree. 5

Bachelor's degree. 6
Adapted from Question 3, 2019 American Community Survey

(ACS).

Adapted from Question 4, 2019

ACS.

Adapted from Question 3, 2019

ACS.

Adapted from Question 6, 2020

Census.

Adapted from Question 7, 2020

Census.
Adapted from Question 19, 2019

ACS. 
Advanced degree (e.g. master's degree, professional degree, or doctorate). 7

Other:

S7 Are you currently a student? Select one only.

Yes, I'm enrolled in a 4-year program. 1

Yes, I'm enrolled in a 2-year program. 2

Yes, I'm enrolled in some other program (specify) 3

No. 4

S8 Are you currently employed? This includes self-employment. Select one only.

Yes (full time). 1

Yes (part time). 2

No, I've been looking for work for the past 0-3 months. 3

No, I've been looking for work for the past 3-6 months. 4

No, I've been looking for work for longer than 6 months. 5

No, and I am not currently looking for work. 6

I am retired. 7

S9 What is your annual household income from all sources, before taxes and other deductions from pay? Please include all wages or salaries, social security or other

retirement income, child support, public assistance, business income, and all other income. Select one only.

$\$ 10,000$ or less 1

Between $\$ 10,001$ and $\$ 20,0002$

Between $\$ 20,001$ and $\$ 30,0003$

Between $\$ 30,001$ and $\$ 45,0004$

Between $\$ 45,001$ and $\$ 60,0005$

Between $\$ 60,001$ and $\$ 75,0006$

Between $\$ 75,001$ and $\$ 100,0007$

More than $\$ 100,0008$

Prefer not to answer X

S10 Have you applied for unemployment insurance (also known as unemployment benefits) within the past three years (i.e. from February 2017 to February 2020)? Select one only.

Yes. 1

No. 2

I don't know. 3

S11 How many children do you have that live at home with you, or who you have regular responsibility for?

S12 Have you ever served on active duty in the U.S. Armed Forces, Reserves, or National Guard? Select one only.

Adapted from Questions 27-28, 2019

Never served in the military. 1

Only on active duty for training in the Reserves or National Guard. 2

Now on active duty. 3

Designed to determine if respondents have previously enrolled in unemployment benefits. 
On active duty in the past, but not now. 4

S13 Please select all of the conditions that apply to you. Select all that apply.

Adapted from Questions 18-20, 2019

I am deaf or have serious difficulty hearing. 1

I am blind or have serious difficulty seeing even when wearing glasses). 2

Because of a physical, mental, or emotional condition, I have serious difficulty

concentrating, remembering, or making decisions. 3

I have serious difficulty walking or climbing stairs. 4

I have difficulty dressing or bathing. 5

Because of a physical, mental, or emotional condition, I have difficulty doing errands

alone such as visiting a doctor's office or shopping. 6

None apply. 7

Prefer not to answer. 8

S14 What month and year were you last employed?

S15 (If S14 is January 2020 or later) Are you currently unemployed because of the coronavirus (COVID-19) crisis? Select one only.

Yes. 1

No. 2

I don't know. 3

S16 (If S15 is 1) How likely or unlikely do you think it is that you could return to your previous job after the coronavirus (COVID-19) crisis? Select one only.

Very likely. 1

Somewhat likely. 2

Neither likely nor unlikely. 3

Somewhat unlikely. 4

Very unlikely. 5

S17 (If S14 is January 2020 or later) Have you applied for unemployment insurance (also known as unemployment benefits) within the past month? Select one only.

Yes. 1

No. 2

I don't know. 3

S18 (If S17 is Yes) Were you successful in your application? Select one only.

Yes. 1

No. 2

My application is pending. 3

S19 (If S17 is Yes) How hard or easy was it to apply for unemployment insurance?

See S15.

Select one only.

Very hard. 1

Somewhat hard. 2

Neither hard nor easy. 3

Somewhat easy. 4

Very easy. 5 
S20 (If 17 is No) Why have you not applied for unemployment insurance? Select all that apply.

I'm not eligible. 1

I don't know my eligibility status. 2

I don't know how to do it. 3

The unemployment insurance office or agency is closed. 4

The system is down or overloaded. 5

I haven't been able to contact the office or agency. 6

Other:

S21 (If S8 is 1,2) How likely or unlikely do you think it is that you will lose your job or be laid off due to the COVID-19 pandemic?

Very likely. 1

Somewhat likely. 2

Neither likely nor unlikely. 3

Somewhat unlikely. 4

Very unlikely. 5

S22 Has the coronavirus (COVID-19) crisis made you want to change your job or occupation in the future? Select one only.

Yes, I want to change both my job and occupation. 1

Yes, I want to change my job. 2

Yes, I want to change my occupation. 3

No, I do want to change my job or occupation. 4

S23 How has the coronavirus (COVID-19 crisis) changed your future career plans?

S24 In the past month, how often did you feel anxious or stressed? Would you say never, some days, most days, or every day? Select one only.

Never. 1

Some days. 2

Most days. 3

Every day. 4

Prefer not to answer. 5

S25 (If S8=1,2) What is your main job? (For example, 4th grade teacher, or plumber, or self-employed IT consultant). Write in the space below. (If S8=3,4,5) Think back to your last job. What was your main job? (For example, 4th grade teacher, or plumber, or selfemployed IT consultant). Write in the space below.

S26 (If S8=1,2) Which industry do you think best describes your main job? Select one only. (If $S 8=3,4,5$ ) Which industry do you think best described your last job? Select one only.

Agriculture, forestry, fishing, and hunting (e.g. a grain farm, a forest nursery) 1

Mining (e.g. a coal mine, a shale oil extraction plant) 2

Construction (e.g. a residential construction company, a road building company) 3

Manufacturing (e.g. a paper mill, an electrical component manufacturing plant) 4
See S15.

Designed in partnership with the Rhode Island Department of Labor and Training to assess the impact of the COVID-19 pandemic on unemployment.

See S21.

See S21.

Adapted from Question 42e, 2019

ACS.

Categories taken from the US

Bureau of Labor Statistics' industry classifications:

https://www.bls.gov/ces/naics/. 
Utilities (e.g. a natural gas distributor, a water processing plant) 5

Wholesale trade (e.g. a motor vehicle part wholesaler, an apparel wholesaler) 6

Transportation and warehousing (e.g. a freight truck company, a warehouse and storage facility) 7

Information (e.g. a radio broadcaster, a cable company) 8

Financial activities (e.g. a bank, a real estate company) 9

Professional and business services (e.g. an accounting firm, a law practice) 10

Educational services (e.g. an elementary school, a trade school) 11

Health care and social assistance (e.g. a primary care clinic, a nursing home) 12

Leisure and hospitality (e.g. a restaurant, a hotel) 13

Government (e.g. the state government, the National Park Service) 14

Armed forces (e.g. the US Air Force, the U.S. Coast Guard) 15

Self-employed (e.g. a freelance graphic designer, an electrician) 16

Retail trade (e.g. a sporting goods store, a grocery store) 17

I don't know 18

Other: 19

S27 (If S8=1,2) How did you usually get to work last week? Select one only. (If $\mathrm{S} 8=3,4,5)$ How did you usually get to work at your last job? Select one only.

Adapted from Question 32, 2019

Car, truck, or van 1

Bus or trolley bus 2

Streetcar or trolley car 3 Subway or train 4

Railroad 5

Ferryboat 6

Taxicab or ridesharing service (e.g. Uber) 7

Motorcycle 8

Bicycle 9

Walked 10

Worked at home 11

Other: 12

\section{A.1.2 Main Questions}

1 From what you have told us, you qualify for our survey. The survey will take you approximately 20 to 25 minutes to complete. At some points there's a lot to read, but please read it slowly and carefully to be sure you understand all of the information. If you cannot complete the whole survey at one time, you will be able to take a break and come back to complete the survey later. To pick up where you left off, just re-click on the link inviting you to the survey.

Your answers will be kept strictly confidential, and you will not be individually identified. 
The survey is about job training programs, and what things are important to people like you when you look for opportunities to gain skills for your career. First, we'll ask you for a few more details about how you think about your current or recent jobs, and then we'll ask you to think about what would be important if you were to look for a job training program in the near future.

Click continue button.

2 (If $\mathrm{S} 8=1,2$ ) How much in total do you currently earn yearly at your job(s), including

Adapted from Question 43, 2019

all wages or salaries, commissions, bonuses, and tips? (If $S 8=3,4,5$ ) How much in total ACS.

did you earn at your job(s) yearly when you were last employed, including all wages or salaries, commissions, bonuses, and tips? Write in the space below.

3 (If $S 8=1,2$ ) How many hours do you typically work per week in total, across all jobs?

(If $S 8=3,4,5$ ) How many hours did you typically work per week when you were last employed, in total across all jobs? Please round up to the nearest hour. Do not use commas or decimals.

4 (If $\mathrm{S} 8=1,2)$ How many weeks do you typically work per year in total, across all jobs?

Please include paid leave as work. (If S8=3,4,5) How many weeks did you typically

work per year when you were last employed, in total across all jobs? Please include paid leave as work. Please round up to the nearest week. Do not use commas or

decimals.

5 How often, if ever, do you have trouble paying your regular monthly bills and expenses? Select one only.

Every month 1

Most months 2

About half the time 3

Less than half the time 4

Every once in a while 5

Never 6

6 (If S8=1,2) How often, if ever, do you worry about losing your job(s)? Select one only.

See 5.

Every month 1

Most months 2

About half the time 3

Less than half the time 4

Every once in a while 5

Never 6

7 Suppose that you have an emergency expense that costs $\$ 400$. Based on your current financial situation, how would you pay for this expense? Select all that apply.

Adapted from Question EF3, Federal With the money currently in my checking/savings account or with cash. 1 Reserve Survey on the Economic

Put it on my credit card and pay it off in full at the next statement. 2

Well-Being of U.S. Households

(SHED).

${ }^{1}$ https://www.pewtrusts.org/ /media/assets/2013/02/20/pew_choosing_borrowing_payday_feb2013-(1).pdf 
Put it on my credit card and pay it off over time. 3

Use money from a bank loan or line of credit. 4

Borrow from a friend or family member. 5

Use a payday loan, deposit advance, or overdraft. 6

Sell something I own. 7

I wouldn't be able to pay for the expense right now. 8

Other:

8 In the last 90 days, have you received money from any of the following sources? If so, See 5.

how many times did you receive money and what was the total amount you received?

Borrowed money from a friend

Borrowed money from family

Sold or pawned personal possessions

Went to check casher

Used a payday lender/cash advance vendor (examples: Advance America, Check 'n Go)

Use a credit card to receive a cash advance

Received money as a gift

G1. How many times did you do each of the following in the last 90 days? Select one

of: a. Never / b. 1 time / c. 2-5 times / d. More than 5 times

G2. How much in total did you receive? Select one of: a. \$10-25 / b. \$25-50 /c. \$50-75 /

d. More than $\$ 75$

9 [If any value in $8 \mathrm{G} 1=\mathrm{b}, \mathrm{c}, \mathrm{d}$ ] Which expenses did you use the money for? Select all that See 5 .

apply.

To pay rent/mortgage. 1

To pay for food/groceries. 2

To pay for utilities. 3

To cover a credit card bill. 4

To buy medications. 5

To cover unexpected medical costs. 6

To cover unexpected car costs. 7

To cover an emergency. 8

To buy something nice for myself/my family. 9

To pay for transportation. 10

Other:

10 Now, we're going to ask you some questions about job training programs.

Have you ever enrolled in any training program or course to learn specific job skills?

(For example, computers, car repair, truck driving, nursing, day care, welding, or any other job skills?) This does NOT include on-the-job training. Select one only.

Yes. 1

Designed based on a convenience survey and in-depth interviews that we conducted in Rhode Island

Department of Labor field offices. 
I've considered it, but never taken one. 2

No, I have not taken one or considered taking one. 3

11 (If Q10=1) Did you complete the program? If so, did you get a certificate or diploma See 10. for completing the program? Select one only.

Yes, I completed the program and received a certificate or diploma. 1

Yes, I completed the program, but did not receive a certificate or diploma. 2

No, I did not complete the program. 3

12 (If Q11=1) What certificate or diploma did you receive? Please write the certificate See 10.

or diploma title in the space below. (If Q11=2) What was the title of the program?

Please write the program title in the space below.

13 (If Q11=3) Why did you not complete the program? Please rank the top 3 reasons

See 10 .

from most important to least important, with 1 being the most important, 2 being the

next most important reason, and so on.

The program was too expensive to complete. 1

I was not able to get a scholarship or the funding needed to complete it. 2

I decided I didn't need it. 3

People around me thought I shouldn't complete it. 4

I had a bad experience. 5

I didn't have transportation to attend. 6

I didn't have the time to complete it. 7

The training program was too far from my home. 8

I didn't think it was worth the money and time investment. 9

I was not sure if it would result in a better job or career. 10

It wasn't teaching me the skills I wanted to learn. 11

Other:

14 (If $\mathrm{Q} 10=2,3$ ) Why have you not enrolled in a training program? Please rank the top 3 See 10. reasons from most important to least important, with 1 being the most important, 2

being the next most important reason, and so on.

I've never heard of a training program. 1

They are too expensive. 2

I am not able to get a scholarship or funding. 3

I don't feel I need it. 4

People around me think I shouldn't take one. 5

I know someone who had a bad experience. 6

There are no programs I'm interested in available to me. 7

I don't have transportation to attend one. 8

I don't have the time. 9

The training programs are too far from my home. 10

I don't think it's worth the money and time investment. 11

I am not sure if it would result in a better job, career, or skills. 12

Other: 
15 (If Q10=1) What kind of program(s) have you enrolled in? (If Q10=2) What kind of program(s) might you be interested in enrolling in? Please rank the top 3 reasons from most important to least important, with 1 being the most important, 2 being the next most important reason, and so on.

Agriculture and related (e.g. cattle management, harvesting). 1

Architecture and related services (e.g. architectural technology, architectural

management). 2

Basic skills and developmental/remedial education (e.g. GED). 3

Biological and biomedical sciences (e.g. zoology, toxicology). 4

Business, management, marketing, and related support services (e.g. project

management, accounting). 5

Construction (e.g. carpentry, masonry). 6

Communications technologies/technicians and support services (e.g. broadcasting

technician). 7

Computer and information sciences and support services (e.g. computer programming, system administrator) 8

Educational services (e.g. school guidance counselor). 9

Engineering technologies and engineering-related fields (e.g. heating technician, occupational safety technician. 10

Esthetic services (e.g. barber, esthetician). 11 Environmental services (e.g. prevention of healthcare-associated infection, solar energy technician). 12

Financial activities (e.g. financial planning, banking support services) 13

Health professions, related programs, knowledge, and skills (e.g. nursing, radiology

technician) 14

Homeland security, law enforcement, firefighting and related services (e.g. firefighter, police) 15

Interpersonal and social skills (e.g. mediation, conflict resolution) 16

Industrial services (e.g. crane operation, material handling) 17

Leisure and hospitality (e.g. bartending, hotel administration) 18

Manufacturing (e.g. robotics technician, machine operation) 19

Mechanic and repair technologies/technician (e.g. industrial mechanic, motor vehicle

maintenance) 20

Military technologies and applied sciences (e.g. signals intelligence, military

information systems) 21

Mining, quarrying, and oil and gas extraction (e.g. petroleum technology technician) 22

Personal and culinary services (e.g. pastry chef, kitchen assistant) 23

Physical sciences (e.g. meteorology, forensic chemistry) 24

Precision production (e.g. welding, woodworking) 25

Science technologies/technician (e.g. nuclear technician, lab technician) 26

Transportation and materials moving (e.g. truck driving, flight crew) 27

Wholesale and retail trade (e.g. logistics, marketing) 28 
Other:

16 (If $\mathrm{Q} 10=1$ ) What were you hoping to get from your training program? (If Q10=2,3)

See 10.

Imagine that you were to enroll in a training program to learn specific job skills. What would you hope to get out of it? (If Q10=1) What were you hoping to get from your training program? (If $\mathrm{Q} 10=2,3$ ) Imagine that you were to enroll in a training program to learn specific job skills. What would you hope to get out of it? Please rank the top 3 reasons from most important to least important, with 1 being the most important, 2 being the next most important reason, and so on.

A job with more security. 1

A job with better wages. 2

A job with more potential for higher earnings over time. 3

More job satisfaction. 4

A job with more flexible hours. 5

A job in a different sector. 6

A promotion at my current job. 7

A better chance at finding a job (if currently unemployed). 8

Respect from my family/friends/community. 9

Personal fulfillment or interest. 10

To provide for my family. 11

Other:

17 (If $S 4=1,2$ ) Please imagine that you are unemployed, and are... (If $S 4=3,4,5$ ) Please imagine that you are.......considering taking some time in the next few months to complete a training program in (random one of selected responses from Q15).

18 Which of the following pieces of information would you want to see about each training program to feel confident you will be able to choose the program that is best for you? Please rank the top 5 pieces from most important to least important, with 1 being the most important, 2 being the next most important reason, and so on. Total cost of the program including any grants or discounts you qualify for. 1 Length of the program: how many hours per week. 2

Length of the program: how many weeks the program lasts. 3

Location of the program and distance from your house (e.g. address and town). 4

Whether it fits with your schedule. 5

What type of people typically enroll in this program, e.g. the typical earnings of people who enroll before they begin the program. 6 
The typical earnings of people who enroll in the program, six months after enrolling. 7 The typical earnings of people who enroll in the program, two years after enrolling. 8 How likely someone who enrolls in the program is to be employed, six months after enrolling. 9

How likely someone who enrolls in the program is to be employed, two years after enrolling. 10

How likely someone who enrolls in the program is to be employed in the specific sector you are getting trained for, six months after enrolling. 11

How likely someone who enrolls in the program is to be employed in the specific sector you are getting trained for, two years after enrolling. 12

How likely people who enroll in the program are to successfully complete and graduate from the program. 13

Whether the program offers a certificate or industry qualification for completing the program. 14

19 Are there any other pieces of information not included on the list above that you would want to see? Please explain.

\section{A.1.3 Conjoint-Design Questions}

20 Now, we're going to ask you to make some choices between different hypothetical training programs.

21 (If $S 8=1,2$ ) Please imagine that you are unemployed, and are... (If $S 8=3,4,5$ ) Please imagine that you are... ...considering taking some time in the next few months to complete a training program in (Q15 response selected in Q17) to gain additional or new skills and further your career potential. You go to your local Department of Labor website to find programs that you might be interested in. Programs are offered by different training schools around you. You have to choose which training program and school to attend.

22 Suppose that after looking at possible training program choices, you've narrowed the options down to just a few specific programs. All of the program options are available to you immediately. However, the programs differ in several ways:

a. Cost: How much the typical person must pay out-of-pocket in order to attend the program. A cost of $\$ 0$ means that the government has a program to cover the entire cost for you.

b. Travel time: How long it will take the typical person to get to the training school for each class, one way.

c. Completion rate for past students: The percentage of students who start the program who complete it and successfully graduate within the allotted time.

d. Typical earnings for past students, after enrolling: Typical earnings one year after enrolling in the program for people who enrolled in the program in the past. This includes those who didn't necessarily complete the full program. e. What the typical past student would have earned, had they not enrolled: Typical earnings for past students one year later, if the students had not enrolled in the program. 
f. Typical percentage increase in earnings for past students: How much more money the typical student earns one year after enrolling in the program, compared to what they would have earned had they not enrolled. This will be shown as a percentage increase in earnings.

g. Typical unemployment rate for past students: Percentage of people who enrolled in this program who are unemployed (are not working), one year after enrolling.

23 In each of the following questions, we'll show you three training programs, and ask you to: i) rank them in order of preference, and ii) tell us whether you would rather enroll in your highest-ranked training program, or no program at all.

24 As you think carefully about the three program choices, please make the following assumptions:

a. Suppose that you are really choosing a training program to enroll in, and that you have determined that the choices on the screen are the three best options available to you.

b. The programs differ in the information shown here only, and you should consider everything you are told about them. They are identical in all other respects that matter to you (for example, training subject matter, type of teacher, and time of class).

Click "I have read this carefully and understand this information."

The following Questions 25-54 implement the six conjoint design model described in Table 1. Each set of five questions is repeated for each of the six conjoint design models.

25, 30, 35, 40, 45, 50 If these three new training programs below were your only options, which one would you choose? Rank your program preferences from 1-3 in the boxes below, with the program you MOST prefer as number 1, and the program you LEAST prefer as number 3.

\begin{tabular}{|c|c|c|c|c|}
\hline & Training Program \#1 & Training Program \#2 & Training Program \#3 & Conjoint Model \\
\hline Cost: & $\ldots$ & $\ldots$ & $\ldots$ & $1,2,3,4,5,6$ \\
\hline Length: & $\ldots$ & $\ldots$ & $\ldots$ & $1,2,3,4,5,6$ \\
\hline Travel time: & $\ldots$ & $\ldots$ & $\ldots$ & $1,2,3,4,5,6$ \\
\hline $\begin{array}{l}\text { Completion rate for past } \\
\text { students: }\end{array}$ & $\ldots$ & $\ldots$ & $\ldots$ & 2,3 \\
\hline $\begin{array}{l}\text { Typical earnings for past } \\
\text { students, after enrolling: }\end{array}$ & $\ldots$ & $\ldots$ & $\ldots$ & $3,4,6$ \\
\hline $\begin{array}{l}\text { What the typical past } \\
\text { student would have } \\
\text { earned, had they not } \\
\text { enrolled: }\end{array}$ & $\ldots$ & $\ldots$ & $\ldots$ & 4 \\
\hline $\begin{array}{l}\text { Typical percentage } \\
\text { increase in earnings for } \\
\text { past students: }\end{array}$ & $\ldots$ & $\ldots$ & $\ldots$ & 5 \\
\hline $\begin{array}{l}\text { Typical unemployment } \\
\text { rate for past students: }\end{array}$ & $\ldots$ & $\ldots$ & $\ldots$ & 6 \\
\hline
\end{tabular}




\section{Select ranking:}

$26,31,36,41,46,51$ If you were to actually choose a training program today from the options above, and only had the information above to go on, would you be willing to enroll in and pay for the program that you ranked first, or no program at all? Select one only.

Yes, I would be willing to enroll in and pay for the program I ranked first 1

No program at all 2

I'm not sure 3

27, 32, 37, 42, 47, 52 Why, or why not? Please write your response below.

$28,33,38,43,48,53$ Do you believe that if you really chose the program that you ranked first, you would earn more and/or achieve a more fulfilling career after completing the program than you do now? Please select one option.

Yes 1

No 2

I'm not sure 3

29, 34, 39, 44, 49, 54 Why, or why not? Please write your response below.

\section{A.1.4 Debriefing Questions}

55 We're almost done now, but we just have a few more questions about what things were important to you as you made your choices about a training program. Different people go about answering questions like these in different ways. On the screens that follow, we will show a number of statements that other people have made about how and why they answered the questions in the way that they did.

When each statement appears, please select a number between 1 and 5 to indicate how well that statement describes the way that you personally thought about your own answers to those questions. A " 5 " answer means that the statement "describes me perfectly," and a "1" answer means the statement "doesn't describe me at all."

a. "The choices I was asked to make were realistic ones for me."

b. "I didn't fully understand some of the program features I was being asked to consider."

c. "The information that I was shown in the first few choice questions when choosing a training program felt relevant to what I wanted to know."

d. "The information that I was shown in the last few choice questions when choosing a training program felt relevant to what I wanted to know."

e. "If I were really choosing a training program in the future, I would want the information about typical earnings and changes in typical earnings after enrolling in a program that I was shown."

f. "Please select "Doesn’t describe me at all" for this question (this is just for quality control purposes)." 
56 What else would you want to know when deciding whether to enroll in a training program? Please write in the space below.

57 We're constantly trying to improve how we conduct our surveys. If you have any feedback on how we could improve our surveys, please let us know. Please write in the space below.

58 Thank you very much for your time while taking this survey. We appreciate your responses! 